\title{
Identification of deubiquitinase targets of isothiocyanates using SILAC-assisted quantitative mass spectrometry
}

\author{
Ann P. Lawson ${ }^{1}$, Daniel W. Bak², D. Alexander Shannon², Marcus J.C. Long ${ }^{3,7}$, \\ Tushara Vijaykumar ${ }^{4,8}$, Runhan $\mathbf{Y u}^{5}$, Farid El Oualid ${ }^{6}$, Eranthie Weerapana ${ }^{2}$ and \\ Lizbeth Hedstrom ${ }^{1,5}$ \\ ${ }^{1}$ Department of Biology, Brandeis University, Waltham, MA 02453-9110, USA \\ ${ }^{2}$ Department of Chemistry, Merkert Center, Boston College, Chestnut Hill, MA 02467-3860, USA \\ ${ }^{3}$ Graduate Program in Biochemistry and Biophysics, Brandeis University, Waltham, MA 02453-9110, USA \\ ${ }^{4}$ Graduate Program in Molecular and Cellular Biology, Brandeis University, Waltham, MA 02453-9110, USA \\ ${ }^{5}$ Department of Chemistry, Brandeis University, Waltham, MA 02453-9110, USA \\ ${ }^{6}$ UbiQ, 1098 XH Amsterdam, The Netherlands \\ ${ }^{7}$ Current address: Department of Chemistry and Chemical Biology, Cornell University, Ithaca, NY 14853, USA \\ ${ }^{8}$ Current address: Sanofi Genzyme, Framingham, MA 01701, USA \\ Correspondence to: Lizbeth Hedstrom, email: hedstrom@brandeis.edu \\ Keywords: PEITC, USPI, cisplatin, deubiquitinase, cruciferous vegetable \\ Received: June 20,2016 Accepted: March 22, $2017 \quad$ Published: April 20, 2017 \\ Copyright: Lawson et al. This is an open-access article distributed under the terms of the Creative Commons Attribution License 3.0 \\ (CC BY 3.0), which permits unrestricted use, distribution, and reproduction in any medium, provided the original author and source \\ are credited.
}

\section{ABSTRACT}

Cruciferous vegetables such as broccoli and kale have well documented chemopreventative and anticancer effects that are attributed to the presence of isothiocyanates (ITCs). ITCs modulate the levels of many oncogenic proteins, but the molecular mechanisms of ITC action are not understood. We previously reported that phenethyl isothiocyanate (PEITC) inhibits two deubiquitinases (DUBs), USP9x and UCH37. DUBs regulate many cellular processes and DUB dysregulation is linked to the pathogenesis of human diseases including cancer, neurodegeneration, and inflammation. Using SILAC assisted quantitative mass spectrometry, here we identify 9 new PEITC-DUB targets: USP1, USP3, USP10, USP11, USP16, USP22, USP40, USP48 and VCPIP1. Seven of these PEITC-sensitive DUBs have well-recognized roles in DNA repair or chromatin remodeling. PEITC both inhibits USP1 and increases its ubiquitination and degradation, thus decreasing USP1 activity by two mechanisms. The loss of USP1 activity increases the level of mono-ubiquitinated DNA clamp PCNA, impairing DNA repair. Both the inhibition/degradation of USP1 and the increase in mono-ubiquitinated PCNA are new activities for PEITC that can explain the previously recognized ability of ITCs to enhance cancer cell sensitivity to cisplatin treatment. Our work also demonstrates that PEITC reduces the mono-ubiquityl histones H2A and H2B. Understanding the mechanism of action of ITCs should facilitate their use as therapeutic agents.

\section{INTRODUCTION}

Isothiocyanates (ITCs) are the chemoprotective natural products found in cruciferous vegetables such as broccoli, kale and watercress [1-6]. ITCs also have numerous well-documented anticancer activities, including inhibition of proliferation, induction of cell cycle arrest, apoptosis and autophagic cell death, and reduction of the inflammatory response [2, 7-9]. Phenethylisothiocyanate (PEITC) is among the best characterized ITCs due to its potent anticancer activity and low inherent toxicity. A 100 $\mathrm{g}$ serving of watercress releases at least $12 \mathrm{mg}(80 \mu \mathrm{mole})$ of PEITC, resulting in low micromolar concentrations in human plasma [10]. Plasma concentrations of $40 \mu \mathrm{M}$ have 
been observed in rats at doses used in clinical trials (100 $\mu$ mole $/ \mathrm{kg}$ ) [11]. Importantly, cells can accumulate ITCs to concentrations 100-200 times those found in plasma [2].

PEITC perturbs DNA damage repair pathways [12-15] and is considered an epigenetic agent [16-19]. Moreover, PEITC sensitizes cancer cells to cisplatin treatment [12, 13, 15]. PEITC also modulates proteostasis, the inflammatory response, angiogenesis, apoptosis, cell cycle progression, proliferation and autophagy [6]. PEITC reduces the levels of critical proteins in diverse cellular pathways, including MCL1, Bcr-Abl, inhibitor of DNA binding proteins 2 and 3 (ID2 and 3) as well as apoptosis proteins such as X-IAP, cIAPs and survivin $[2,6,9,20$ 24].

While many potential ITC targets have been identified $[2-4,8,25]$, the molecular mechanisms underlying ITC activities are poorly understood. ITCs are electrophiles that form irreversible adducts with amines and reversible adducts with thiols. We previously reported that PEITC and benzylisothiocyanate (BITC) inhibit deubiquitinating enzymes (DUBs) at physiologically relevant concentrations [23]. Inhibition likely involves formation of an adduct with the active site cysteine that resembles the acylenzyme intermediate of the catalytic reaction (Figure 1A, 1B). The carbon-sulfur double bond of this dithiocarbamate adduct is longer than the corresponding carbonyl bond of the thioester intermediate, and thus is expected to capture some of the stabilizing interactions of the transition state of the DUB reaction. Two DUB targets, USP9x and UCH37, were identified, both of which are involved in cancer progression [26, 27]. The inhibition of USP9x can explain the ITC-induced knockdown of MCL1 and Bcr-Abl [21-23, 28].

Ubiquitination is a critical regulator of most cellular processes including the cell cycle, protein turnover, localization and function [29, 30], and the components of the ubiquitin ( $\mathrm{Ub}$ ) pathway are therapeutic targets for cancer and other diseases [31, 32]. DUBs regulate virtually all Ub-dependent processes [33], often protecting their protein substrates from degradation. Consequently, DUB inhibition usually reduces substrate protein levels. Therefore, DUB inhibition can explain the ITCinduced knockdown of critical oncogenic proteins. The approximately 95 DUBs encoded by the human genome are divided into 5 subclasses according to sequence similarities and likely mechanisms of action [30]. Four of these sub-families are cysteine proteases, including Ubiquitin-Specific Proteases (USP), Ubiquitin C-terminal Hydrolases (UCHs), Machado-Joseph domain-containing proteins (MJDs) and Otubain domain-containing proteases (OTUs), and thus potential targets for ITCs.

Here we employ a stable isotope labeling with amino acids in cell culture (SILAC)-assisted mass spectrometry-based (MS) activity profiling proteomics approach to more fully characterize the DUB targets of PEITC [34]. PEITC blocked the labeling of 10 DUBs, including USP1 and 6 other DUBs involved in DNA repair and chromatin remodeling. Inhibition of these DUBs provides a molecular mechanism for the ability of PEITC to sensitize cancer cells to cisplatin.

\section{RESULTS}

\section{PEITC inhibits 10 DUBs}

ITCs form reversible adducts with thiols, which complicates the identification of targets (Figure 1A). We previously used global cysteine activity profiling to show that PEITC does not react promiscuously with protein thiols [23]. PEITC does block the reaction of DUBs with ubiquitin affinity labels, demonstrating that DUBs are privileged ITC targets. Labeling recovered when PEITC concentrations were reduced by dilution, indicating that ITCs form reversible complexes with DUBs. USP9x and $\mathrm{UCH} 37$ have distinctive molecular weights that facilitated their identification as PEITC targets in these gel-based activity profiling experiments [23]. However, additional PEITC targets were clearly present in the 100 - $160 \mathrm{kDa}$ molecular weight region populated by many DUBs. Therefore, we employed a SILAC-assisted mass spectrometry-based activity profiling approach to more fully characterize the DUB targets of PEITC (Figure 1C; $[34,35])$. HeLa cell lysates were prepared from cells labeled with $\left[{ }^{13} \mathrm{C} /{ }^{15} \mathrm{~N}\right]$-L-arginine and $\left[{ }^{13} \mathrm{C} /{ }^{15} \mathrm{~N}\right]-\mathrm{L}-$ lysine (R10K8; heavy) or were unlabeled (R0K0; light). Lysates were treated with PEITC (heavy) or with 1\% DMSO (light) followed by incubation with an equal mixture of biotin-ubiquitin-propargylamide and biotin-ubiquitin-vinyl methyl ester (biotin-Ub-PA/VME). These cell-free lysate experiments employed relatively high concentrations of PEITC $(75 \mu \mathrm{M})$, in keeping with the concentrations that accumulate within cells $[2,36]$. It's important to note that the reaction with the probe is time-dependent and irreversible, so high concentrations of PEITC enable the reaction to proceed long enough to label the greatest number of DUBs, yet still observe inhibition of PEITCsensitive DUBs.

The heavy and light lysates were mixed together and the DUB-probe adducts were enriched on streptavidin beads and subjected to an on-bead tryptic digest. Two biological replicates were analyzed by quantitative MS. Light:heavy ratios were quantified for a total of 35 DUBs that were identified in both biological replicates (Figure 2, Supplementary Tables 1 and 2). PEITC inhibited the labeling of 10 DUBs as determined by a light:heavy ratio of $\geq 4$ together with a statistically significant $p$ value ( $p$ $<0.05$, see Supplementary Table 1). For each of these 10 DUBs, at least 5 unique peptides were identified with consistent light:heavy ratios (Supplementary Table 2). This set included UCH37, but the inhibition of USP9x labeling was below threshold. This discrepancy with our previous report arises from a change in sample 
handling, specifically lysate preparation. USP9x inhibition is observed when lysates are prepared by Dounce homogenization and then treated with PEITC, as reported previously (Supplementary Figure 1A-1C and [23]).
However, USP9x is resistant to PEITC when lysates are prepared by bead lysis as in the SILAC experiment. Protein activities often depend on lysis methods. Note that USP9x inhibition can be observed when cells are
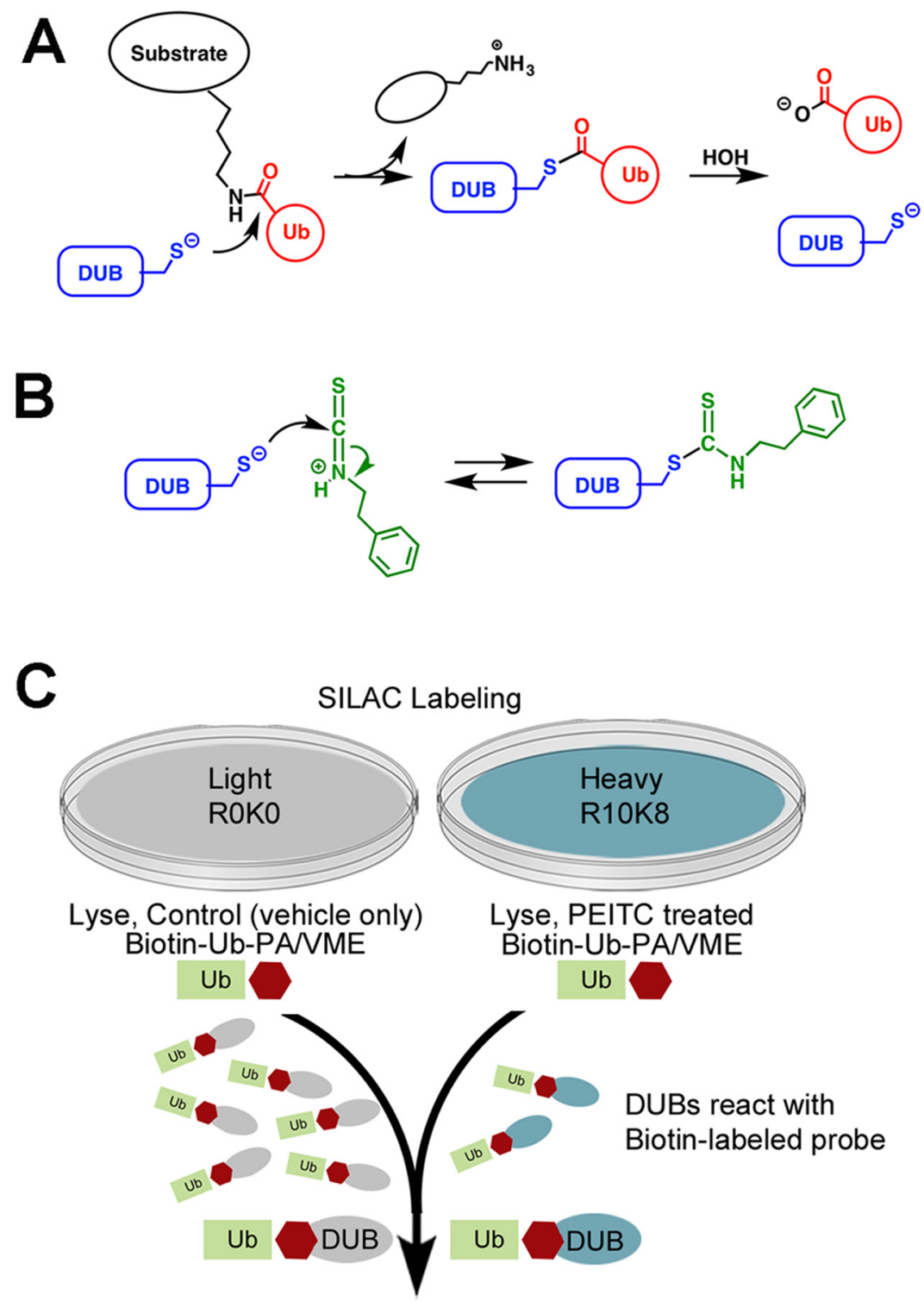

1. Combine lysates

2. Bind to streptavidin beads

3. On-bead tryptic digest

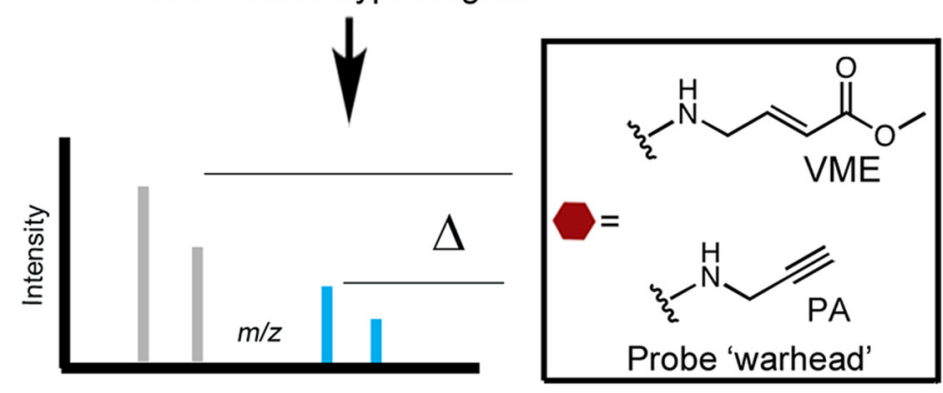

Figure 1: Reaction of PEITC with DUBs. (A) Mechanism of substrate hydrolysis. (B) Proposed mechanism of PEITC inhibition. (C) SILAC-assisted quantitative proteomics strategy to identify DUBs inhibited by PEITC. 
pretreated with PEITC prior to bead lysis and probe treatment [23].

Intriguingly, 7 of the 10 DUBs under-represented in PEITC-treated cells are involved in DNA damage repair and chromatin remodeling (Table 1). Inhibition of these DUBs can explain the effects of PEITC on DNA repair and epigenetic regulation. USP1, USP3, USP16, USP48 and VCPIP1 were only identified in the absence of PEITC (light:heavy ratio defined as 20), suggesting that these DUBs are the most strongly inhibited. To our knowledge, the inhibition of VCPIP1 by PEITC is the first report of inhibition of an OTU domain DUB.

\section{PEITC decreases USP1 levels}

USP1 is one of the best characterized human DUBs [37]. USP1 is a critical regulator of DNA damage repair via the translesion synthesis pathway [37] and the USP1 inhibitor ML323 sensitizes cells to cisplatin [38, 39]. USP1 also deubiquitinates and stabilizes the transcriptional regulators ID1, ID2 and ID3 [40-42]. Thus the inhibition of USP1 can explain several PEITC activities: inhibition of DNA repair, sensitization to cisplatin and decrease in ID protein levels (Table 1) [13, 15, 24]. Therefore, we characterized the effects of PEITC on USP1 in more detail. We confirmed the inhibition of USP1 by PEITC

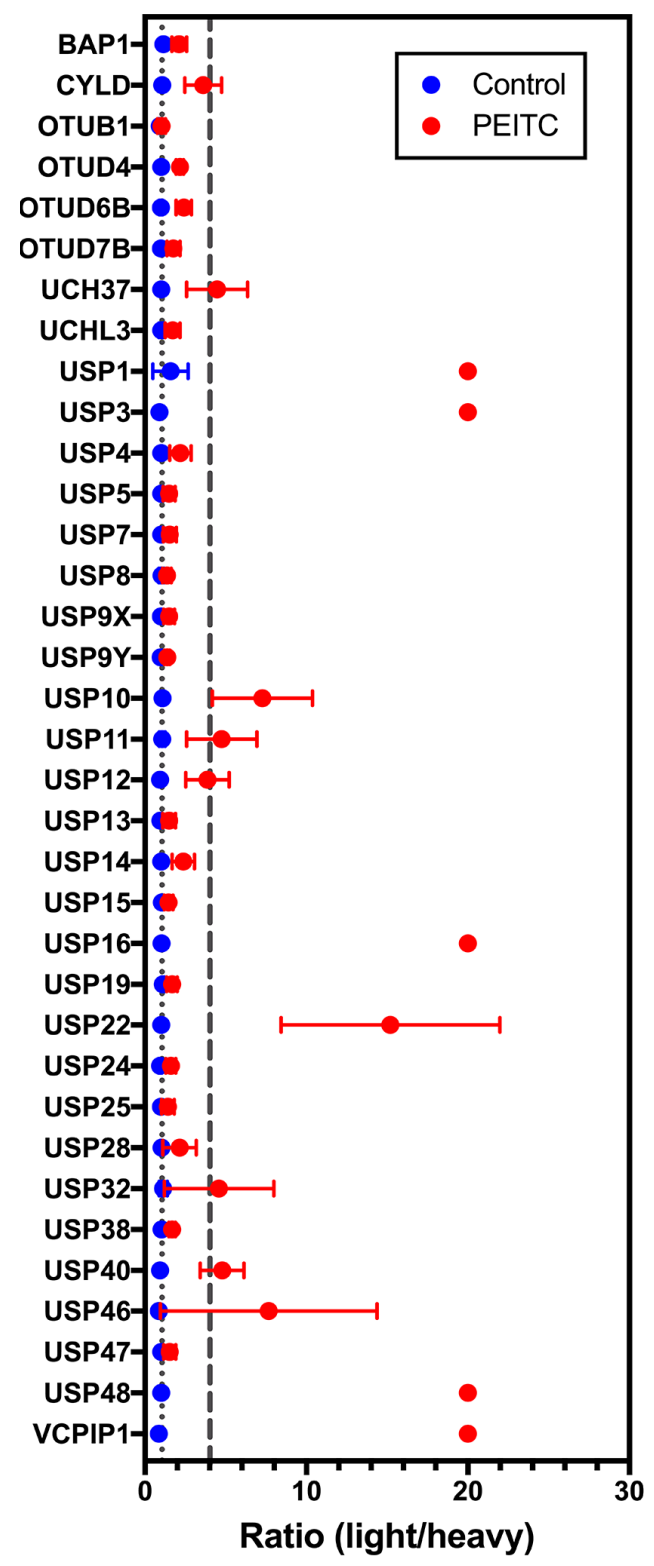

Figure 2: DUB targets of ITCs in HeLa cell lysates identified using SILAC-assisted quantitative MS. Data presented are the mean \pm standard deviation of samples from two independent biological replicates. DUBs are listed only if they appeared in both biological replicates $(n=2)$. The gray dotted line marks a light:heavy ratio of 1 . The gray dashed line marks the threshold light:heavy ratio $=4$. Peptides that are only detected in the light sample are designated an arbitrary ratio value of 20 . In several samples, error bars are smaller than the symbol. 
Table 1: PEITC sensitive DUBs

\begin{tabular}{|c|c|c|c|}
\hline DUB & Cellular Role/Process & Substrate(s) & PEITC \\
\hline USP1 & $\begin{array}{c}\text { DNA repair [37], } \\
\text { Cell cycle }[37,94] \\
\text { Cisplatin resistance [39] } \\
\text { Angiogenesis }\end{array}$ & $\begin{array}{c}\text { PCNA [46] }{ }^{1} \\
\text { FANCD2 [95] } \\
\text { ID1 [40] } \\
\text { ID2 [40] } \\
\text { ID3 [40] }\end{array}$ & $\begin{array}{c}\downarrow \text { (this work) } \\
? \\
? \\
\downarrow[24] \\
\downarrow[24]\end{array}$ \\
\hline USP3 & $\begin{array}{l}\text { Chromatin remodeling [54] } \\
\text { DNA repair [54] } \\
\text { Interferon signaling/ } \\
\text { antiviral immunity [96] }\end{array}$ & $\begin{array}{l}\text { H2A [97] } \\
\text { H2B [54]; } \\
\text { RIG-1 [96] }\end{array}$ & $\begin{array}{l}\downarrow(\text { this work }) \\
\downarrow(\text { this work }) \\
\quad ?\end{array}$ \\
\hline USP10 & $\begin{array}{c}\text { DNA repair [98] } \\
\text { Chromatin remodeling [98] } \\
\text { Autophagy/endocytic recycling [99] }\end{array}$ & $\begin{array}{l}\text { p53 [100, 101] } \\
\text { BECN1 [102] } \\
\text { SNX3 [103] } \\
\text { CFTR }[104]\end{array}$ & $\begin{array}{c}\downarrow \text { Mutant p53 [72] } \\
? \\
? \\
?\end{array}$ \\
\hline USP11 & $\begin{array}{c}\text { DNA repair }[98,105] \\
\text { Chromatin remodeling [105] } \\
\text { Protein stability } \\
\text { Transcription [106] } \\
\text { Inflammatory Response [107] }\end{array}$ & 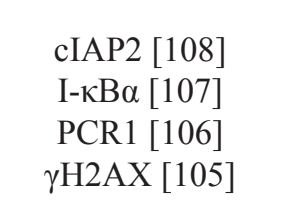 & $\begin{array}{c}\downarrow[109] \\
? \\
? \\
?\end{array}$ \\
\hline USP16 & $\begin{array}{l}\text { DNA repair }[52,110] \\
\text { Chromatin remodeling }[52,110] \\
\text { Cell Cycle }\end{array}$ & $\mathrm{H} 2 \mathrm{~A}[111]$ & $\downarrow$ (this work) \\
\hline USP22 & $\begin{array}{c}\text { Chromatin remodeling [79] } \\
\text { Cell proliferation }[77,79,112] \\
\text { Protein stability } \\
\text { Gene expression }[78,113] \\
\text { Telomere maintenance [114] }\end{array}$ & $\begin{array}{l}\text { H2A }[115] \\
\text { H2B }[116] \\
\text { TRF1 }[114] \\
\text { COX-2 [80] } \\
\text { FBP1 }[81]\end{array}$ & $\begin{array}{c}\downarrow \text { (this work) } \\
\downarrow \text { (this work) } \\
? \\
\downarrow[84] \\
\uparrow \mathrm{p} 21[82,83,117]^{2}\end{array}$ \\
\hline USP40 & $?$ & $?$ & $?$ \\
\hline USP48 & $\begin{array}{l}\text { Inflammation/ } \\
\text { immune response [73] }\end{array}$ & $\mathrm{NF}-\kappa \mathrm{B} / \mathrm{RelA}[73]$ & $\downarrow N F-\kappa B$ gene expression $[74,75]$ \\
\hline UCH37 & $\begin{array}{l}\text { Chromatin remodeling [118] } \\
\text { Cell cycle [119] } \\
\text { Protein homeostasis [27] }\end{array}$ & Polyubiquitin [27] & $\uparrow \mathrm{K} 48$ and K63-linked polyUb [23] \\
\hline VCPIP1 & Golgi Disassembly [86] & $?$ & $?$ \\
\hline
\end{tabular}

1. Abbreviations: RIG-I, retinoic acid-inducible gene 1; PCNA, Proliferating cell nuclear antigen; FANCD2, Fanconi Anemia, Complementation Group D2 ; H2A, histone 2A; H2B, histone H2B; PCR1, polycomb repressive complex 1; FBP1, far upstream element (FUSE)-binding protein 1; COX-2, cyclooxygenase-2; TRF1, Telomeric repeat-binding factor

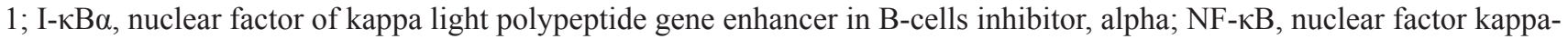
light-chain-enhancer of activated B cells; cIAP2, cellular inhibitor of apoptosis 2; BECN1, Beclin-1; SNX3, Sorting Nexin 3; CFTR, Cystic fibrosis transmembrane conductance regulator.

2. p21 is suppressed by FBP1 [81].

by monitoring the hydrolysis of di-Ub by purified USP1 in complex with its activator UAF1 (Figure 3A, 3B). Dose dependent inhibition was observed, confirming that PEITC is a USP1 inhibitor. We also prepared lysates from HEK293T cells treated with PEITC to determine if USP1 was inhibited in living cells. Clarified lysates were treated with activity probes and USP1 was visualized by immunoblotting to observe the molecular weight shift that occurs with labeling [35, 43, 44] (Figure 3C, 3D). PEITC treatment decreased the ratio of labeled to unlabeled USP1, demonstrating that PEITC inhibits USP1 in living cells (Figure 3C, 3D and Supplementary 

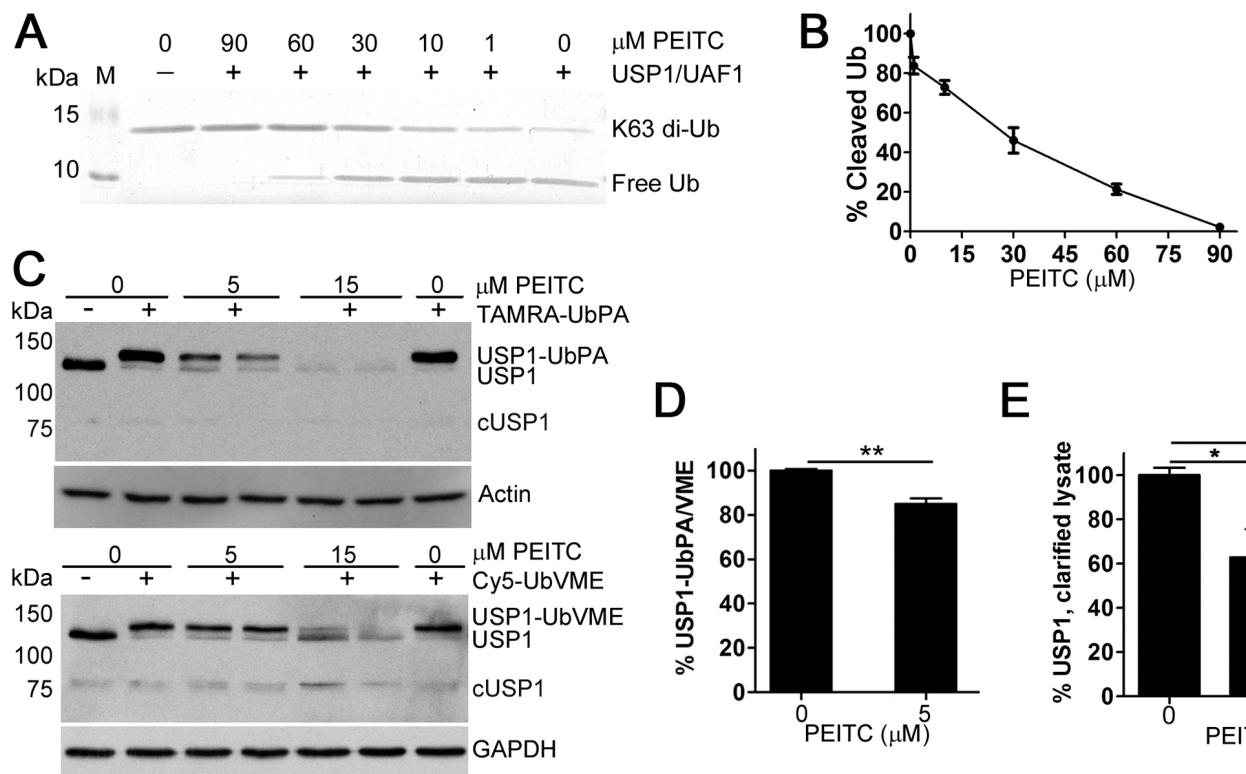

$\mathrm{D}$

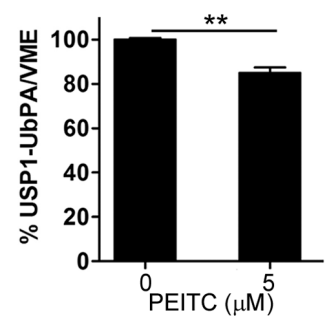

E
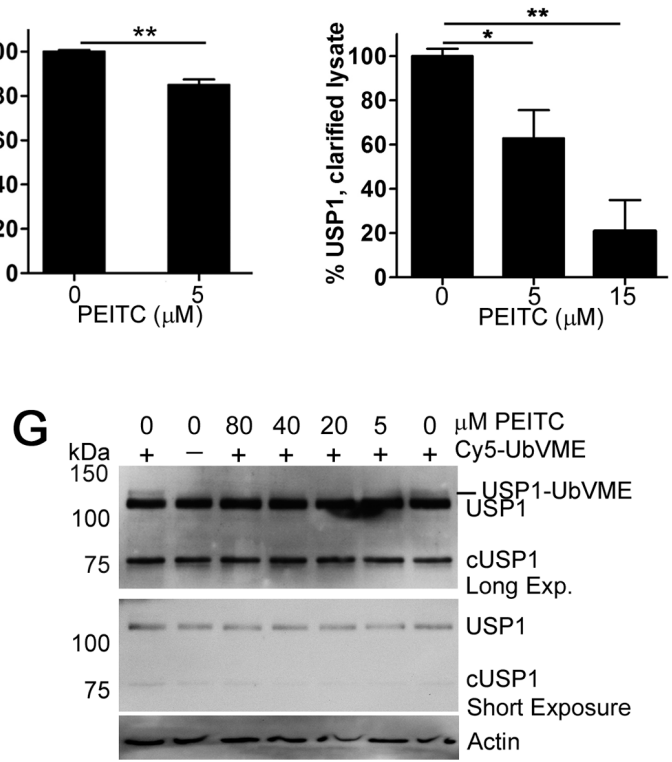
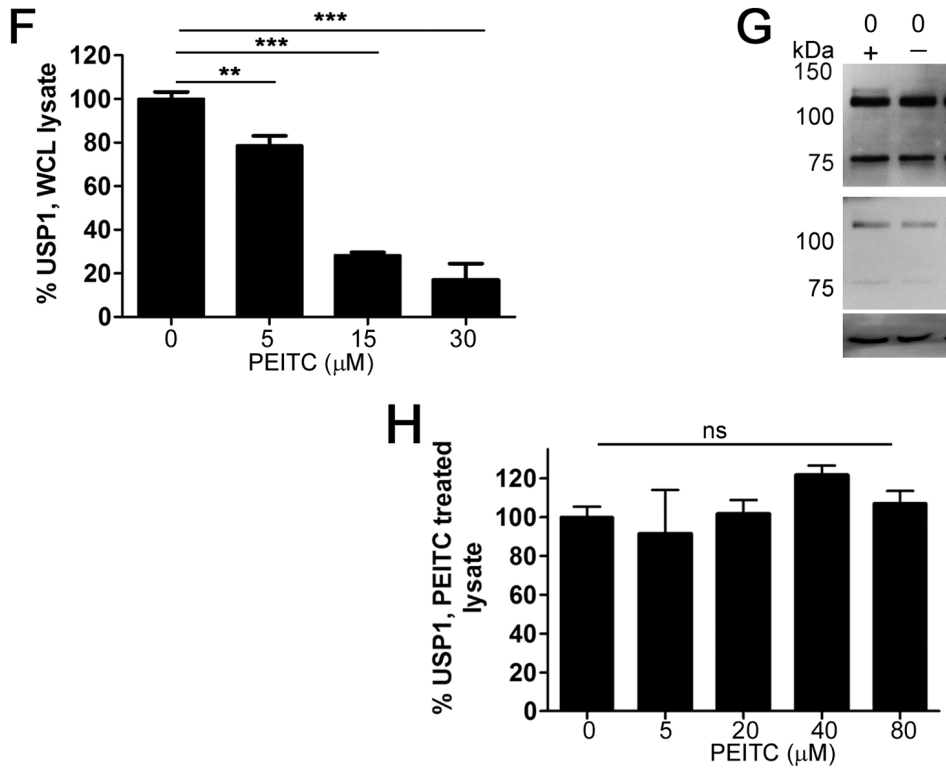

Figure 3: PEITC inhibits recombinant USP1 and leads to USP1 knockdown in living cells. (A) USP1/UAF1 complex $(150 \mathrm{nM})$ was pre-incubated with PEITC or with DMSO control for $8 \mathrm{~min}$ at which time K63-linked di-ubiquitin was added $(3 \mu \mathrm{M})$ and incubated for $10 \mathrm{~min}$ at $37^{\circ} \mathrm{C}$. Experiments were quenched by the addition of reducing loading buffer. Samples were analyzed by SDSPAGE (15\% gel) and the gels stained with InstantBlue (Expedeon). Data are representative of three independent experiments. (B) As in (A) the amount of cleaved (free) ubiquitin was measured and data were normalized to the no inhibitor control. (C) HEK293T cells were incubated with PEITC for $3 \mathrm{~h}$, harvested, washed and lysed with glass beads. Clarified lysates adjusted to $1.6 \mathrm{mg} / \mathrm{mL}$ and treated with TAMRA-Ub-PA $\left(1.2 \mu \mathrm{M}\right.$, top) or with Cy5-Ub-VME $\left(1.2 \mu \mathrm{M}\right.$, bottom) for $8 \mathrm{~min}$ at $25^{\circ} \mathrm{C}$ and analyzed by SDS-PAGE and western blot. 'cUSP1' is cleaved USP1. Actin and GAPDH are shown as loading controls. (D) Clarified lysates were prepared as in (C) and treated with TAMRA-Ub-PA $(1.2 \mu \mathrm{M})$ or with Cy5-Ub-VME $(1.2 \mu \mathrm{M})$ for $8 \mathrm{~min}$ at $25^{\circ} \mathrm{C} . \%$ USP1-Ub-PA/VME was determined (densitometry) by calculating the ratio of the top, USP1-probe conjugated band to total USP1 levels. Data were normalized to the DMSO (vehicle only) control. Data represent mean \pm SD of 4 independent experiments. Representative blots shown in (C). (E) As in (C), total USP1 levels were determined by normalizing the sum of both USP1 bands to actin (or to GAPDH) and DMSO control. Data represent mean \pm SD of 4 independent experiments. (F) HEK293T cells were incubated with PEITC for $3 \mathrm{~h}$ and WCLs were analyzed by SDS-PAGE and western blot. Total USP1 levels were determined by normalizing the USP1 band to the loading control (actin or GAPDH) and to DMSO control. Data represent mean \pm range of at least two independent experiments. See Supplementary Figure 3A for representative blot. (G) A HeLa cell lysate $(1.5 \mathrm{mg} / \mathrm{mL})$ was incubated with PEITC or with DMSO (vehicle only) for $25 \mathrm{~min}$ at $37^{\circ} \mathrm{C}$ at which time Cy5-Ub-VME $(1.2 \mu \mathrm{M})$ was added. Following a $30 \mathrm{~min}$ probe incubation, aliquots (equal volumes) were analyzed by immunoblotting for USP1. Actin is shown as a loading control. (H) As in (G) Total USP1 levels normalized to actin and are relative to the no inhibitor control. Data represent mean $\pm \mathrm{SD}$ of 2 independent experiments. Representative blot shown in $(\mathrm{G})$ 'ns' equals not significant. $\mathrm{P}<0.05$ *; $\mathrm{P}<0.01$ **; $\mathrm{P}<0.001$ *** 
Figure 2A, 2B). USP1 is known to undergo cleavage $[45,46]$ and the cleaved product, which undergoes rapid proteasomal degradation [45], was observed as a faint band with a MW of approximately $75 \mathrm{kDa}$ in some, but not all, USP1 blots (Figure 3C). Surprisingly, PEITC also decreased total USP1 protein levels in a dose dependent manner (Figure 3E). The PEITC-induced knockdown of USP1 was confirmed in whole cell lysates (Figure 3F and Supplementary Figure 3A). USP1 levels were stable in cell lysates (Figure $3 \mathrm{G}, 3 \mathrm{H}$ ), indicating that the USP1 knockdown resulted from the action of PEITC in living cells.

To investigate whether the PEITC-induced knockdown of USP1 was due to proteasomal degradation, HEK293T cells were incubated with PEITC in the presence of the proteasome inhibitor bortezomib (Figure
4A). Bortezomib increased total K48-linked ubiquitination as expected but had no effect on USP1 levels (Figure 4A, 4B and Supplementary Figure 3B). However, when cells were treated with PEITC in the presence of bortezomib, a significant increase in USP1 was detected when compared with PEITC treatment alone (Figure 4A, 4B and Supplementary Figure 3B). We next determined if PEITC treatment increased levels of polyubiquitinated USP1. To facilitate visualization of USP1 ubiquitination, HEK293T cells were transiently transfected with HA-tagged ubiquitin prior to treatment with PEITC, bortezomib or a combination of PEITC and bortezomib. USP1 immunoprecipitated from PEITC or PEITC/ bortezomib treated lysates showed a significant amount of poly-ubiquitination (Figure 4C and Supplementary Figure 3 C). In contrast, USP1 from the bortezomib or
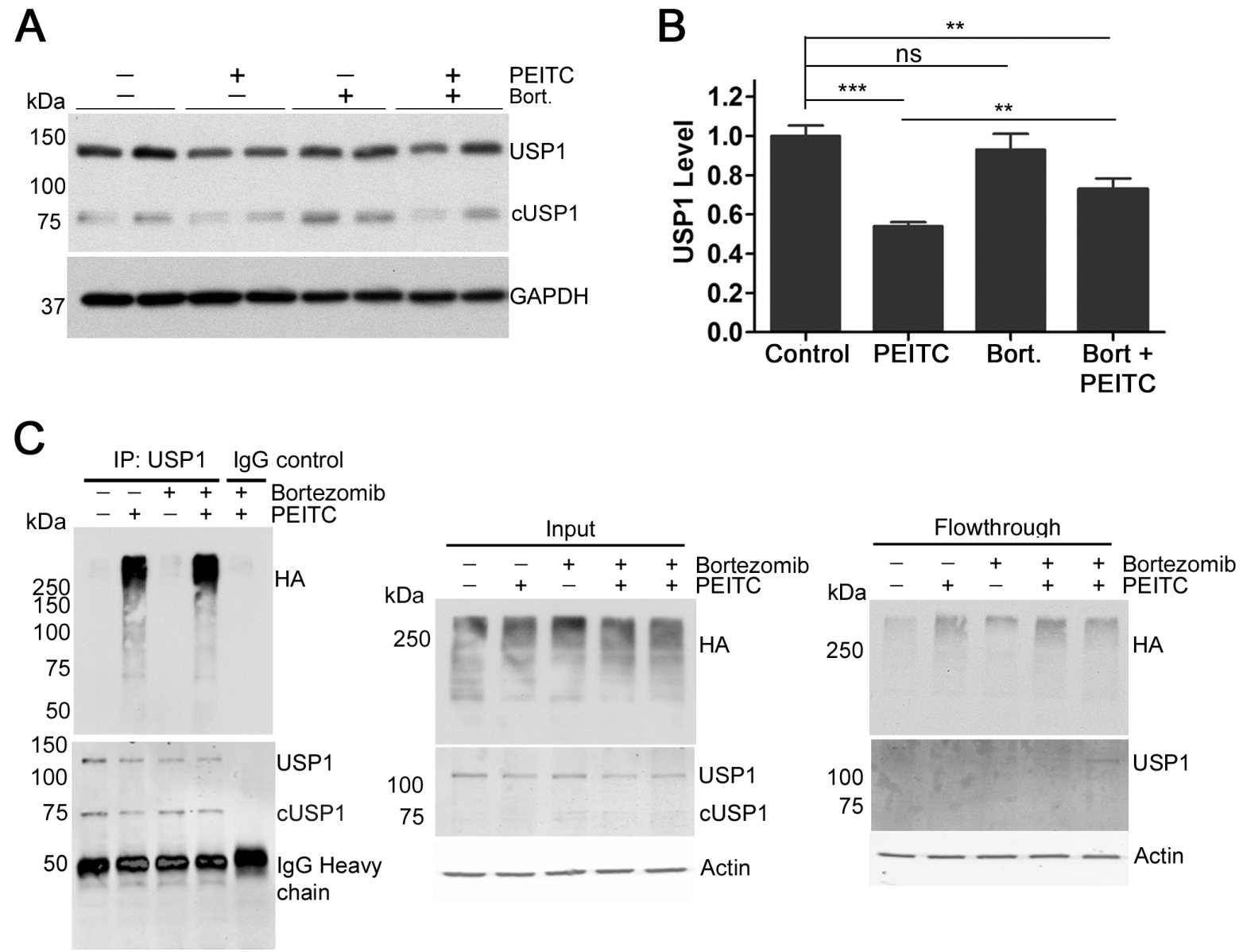

Figure 4: PEITC reduces levels of USP1 by increasing levels of poly-ubiquitinated USP1. (A) HEK293T cells were incubated with PEITC $(15 \mu \mathrm{M})$, bortezomib $(300 \mathrm{nM})$, PEITC $(15 \mu \mathrm{M})$ together with bortezomib (300 nM) or with DMSO (vehicle only) for $3 \mathrm{~h}$ at $37^{\circ} \mathrm{C}$. WCLs analyzed by SDS-PAGE and western blot. Data represent three independent experiments performed in duplicate. (B) As in (A) Data represent mean \pm SD of 3 independent experiments performed in duplicate. Representative blot shown in (A). (C) HEK293T cells were transiently transfected with HA-Ubiquitin using TransIT2020 transfection reagent. $24 \mathrm{~h}$ post-transfection, cells were incubated with PEITC $(15 \mu \mathrm{M})$, bortezomib (300 nM), PEITC (15 $\mu \mathrm{M})$ together with bortezomib (300 nM) or with DMSO (vehicle only) for $3 \mathrm{~h}$ at $37^{\circ} \mathrm{C}$. USP 1 was immunoprecipitated and eluants were probed with anti-HA antibody and anti-USP1 antibody. Actin is shown as a loading control. 
DMSO control lysates contained low or undetectable, levels of polyubiquitination. PEITC does not increase expression levels of $20 \mathrm{~S}$ proteasomal subunits $\beta 1$ or $\alpha 3$ (Supplementary Figure 3D, 3E), which suggests that 26S proteasome levels remain stable upon PEITC treatment. Thus PEITC induces the proteasomal degradation of USP1 by increasing the poly-ubiquitination of USP1.

\section{PEITC increases the ubiquitination of PCNA}

USP1 regulates DNA damage repair by deubiquitinating the DNA clamp Proliferating Cell Nuclear Antigen (PCNA) [39, 46]. Treatment of HEK293T cells with PEITC for $3 \mathrm{~h}$ increased monoubiquityl PCNA (UbPCNA) both in the presence and absence of hydroxyurea, a replication inhibitor known to induce Ub-PCNA (Figure 5A). PEITC increased Ub-PCNA levels to a greater extent than the selective USP1 inhibitor ML323 (Figure 5A). The increase in Ub-PCNA is a new activity for PEITC.

\section{PEITC sensitizes MCF-7 cells to cisplatin}

DNA damaging agents such as cisplatin are widely used in the treatment of highly aggressive, triplenegative breast cancer and BRCA1/2-mutated tumors [47-49]. Wang et al previously reported that PEITC (10 $\mu \mathrm{M})$ potentiates the cytotoxicity of cisplatin $(10 \mu \mathrm{M})$ in the human breast cancer line MCF-7 cells [15]. Since the concentration of PEITC used in these experiments is far greater than the highest plasma concentrations (1 $\mu \mathrm{M})$ observed from dietary consumption $[10,50]$, we chose to examine the dose response of the PEITC and cisplatin interaction. Both PEITC and cisplatin caused a dose and time-dependent decreases in MCF-7 cell viability as measured using the CCK-8 assay (Figure 5B and Supplementary Figure 4A). Cisplatin and PEITC alone reduced $\mathrm{MCF}-7$ cell viability with values of $\mathrm{EC}_{50}$ of $18 \mu \mathrm{M}$ and $37 \mu \mathrm{M}$, respectively, following a $48 \mathrm{~h}$ drug treatment. The reduction in cell viability was potentiated when cells were treated with PEITC and cisplatin together in a 1:1 molar ratio as indicated by the reduced value of $\mathrm{EC}_{50}(6 \mu \mathrm{M})$ (Figure 5B). We next investigated the nature of PEITC's effect on cisplatin killing by performing Bliss independence drug interaction analysis to calculate combination index (CI) values. Synergism is indicated by a CI of less than 1 , additivity by a CI equal to 1 , and antagonism by a CI greater than 1 . Significant synergy was observed when MCF-7 cells were co-treated with PEITC and cisplatin at concentrations of either 12 or $25 \mu \mathrm{M}$ PEITC and $25 \mu \mathrm{M}(7.5 \mu \mathrm{g} / \mathrm{mL})$ cisplatin (CI values of 0.79 and 0.82 , respectively; Figure 5C-5D). The interaction between cisplatin and PEITC was further analyzed using Combenefit [51] to assess three classic drug interaction models, Loewe, Bliss, and the Highest Single Agent (HSA) model. All three models showed strong synergistic effects for the combination of PEITC $(12 \mu \mathrm{M})$ and cisplatin (12 or $25 \mu \mathrm{M})$, in agreement with Wang et al [15] (Figure 5E and Supplementary Figure 4B). Interestingly, combinations of PEITC and cisplatin had antagonistic effects at higher concentrations, likely reflecting the multiple pathways affected by PETIC treatment (Figure 5B and Supplementary Figure 4C-4D).

\section{PEITC reduces levels of mono-ubiquityl histones $\mathrm{H} 2 \mathrm{~A}$ and $\mathrm{H} 2 \mathrm{~B}$}

Three of the PEITC-inhibited DUBs are involved in chromatin remodeling by deubiquitinating histone $\mathrm{H} 2 \mathrm{~A}$ (USP16) or both histone H2A and histone H2B (USP3 and USP22) $[52,53]$. The inhibition of USP3 by PEITC in living cells was confirmed by observing the molecular shift upon probe labeling by immunoblotting (Figure 6A, 6B). USP3 depletion has been shown to increase levels of both mono-ubiquityl H2A (mono-Ub-H2A) and mono-ubiquityl H2B (mono-Ub-H2B) [52, 54]. However, contrary to expectations, treatment of HEK293T cells with PEITC decreased the levels of both mono-Ub-H2A and mono-UbH2B (Figure 6C-6F). Similar observations were obtained in HeLa cells (Figure 6G and Supplementary Figure 5). The broad spectrum DUB inhibitor PR-619 also decreased ubiquitylated histones [55], as do proteasome inhibitors $[55,56]$. This effect has been attributed to depletion of the free ubiquitin pool due to the accumulation of high molecular weight ubiquitin conjugates [56, 57]. Importantly, decreased levels of mono-Ub-H2A and mono-Ub-H2B alter chromatin structure and disrupt DNA damage repair processes [58].

\section{PEITC modifies the catalytic cysteine of $\mathrm{UCH} 37$}

We performed several experiments to further interrogate the mechanism of PEITC inhibition of DUBs. We used UCH37, identified in both our previous report [23] and in the current SILAC experiments (Figure 2), as our model PEITC-sensitive DUB because it is reasonably well characterized, its small size is more amenable to peptide identification and suitable quantities could be obtained by recombinant protein expression. UCH37 is activated by the proteasomal subunit ADRM1 (also known as RPN13) [59]. PEITC inhibits rUCH37/ADRM1 complex binding to active site directed probe, TAMRAUb-PA (Figure 7A) and inhibits $\mathrm{UCH} 37$ in living cells (Supplementary Figure 2C, 2D) [23]. The preincubation of $\mathrm{rUCH} 37 / \mathrm{ADRM} 1$ with PEITC also inhibited the hydrolysis of Ub-Rho110MP (Supplementary Figure 6). No rUCH37/ADRM1 activity recovered when DTT was added after preincubation, indicating that the PEITC adduct with rUCH37/ADRM1 is stable (Supplementary Figure 6). Unfortunately, UCH37/ADRM1 inactivates under these assay conditions, so we can only conclude that the PEITC adduct does not react rapidly with dithiothreitol on the folded enzyme. Nonetheless, the stability of this 
adduct suggested that it might be possible to use MS analysis to determine if the catalytic Cys88 was modified.

Direct detection of the proposed PEITC adduct with the catalytic Cys88 of UCH37 was not feasible by MS analysis due to the instability of this adduct to protein denaturation and trypsin digestion, which must be performed in the presence of reducing thiols to prevent disulfide bond formation. Instead, we sought
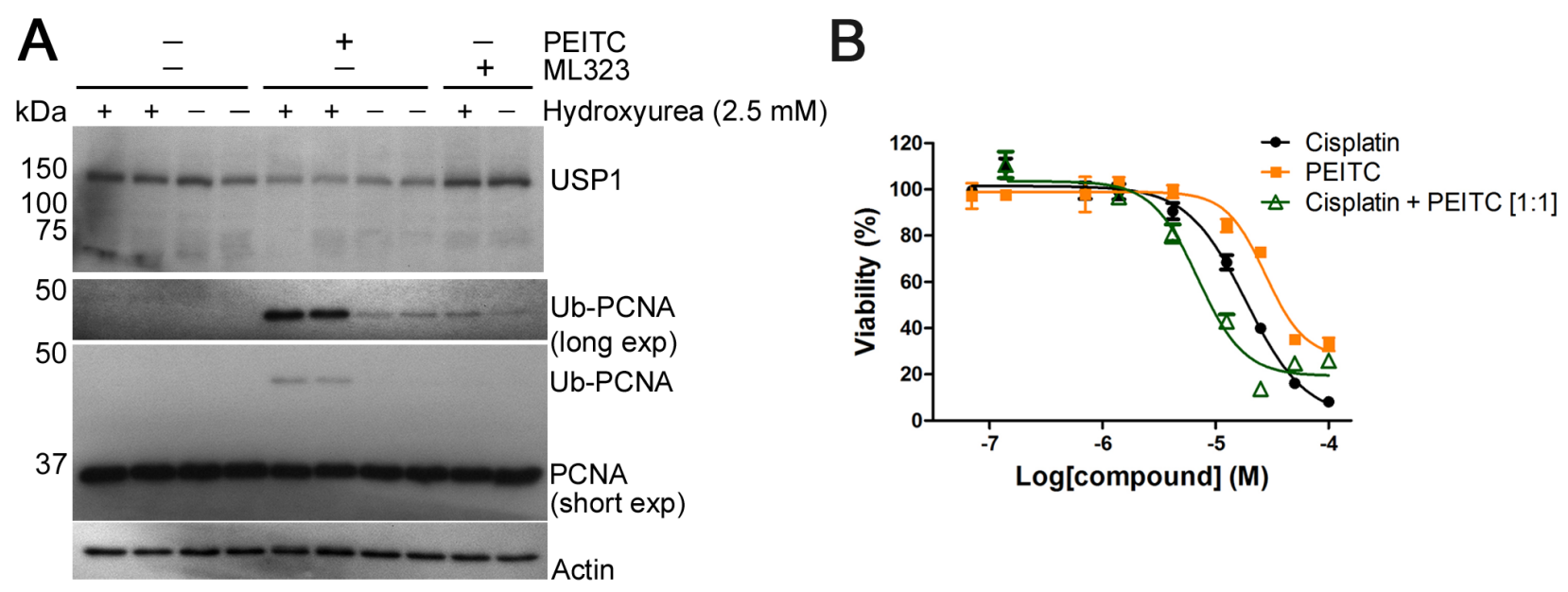

C

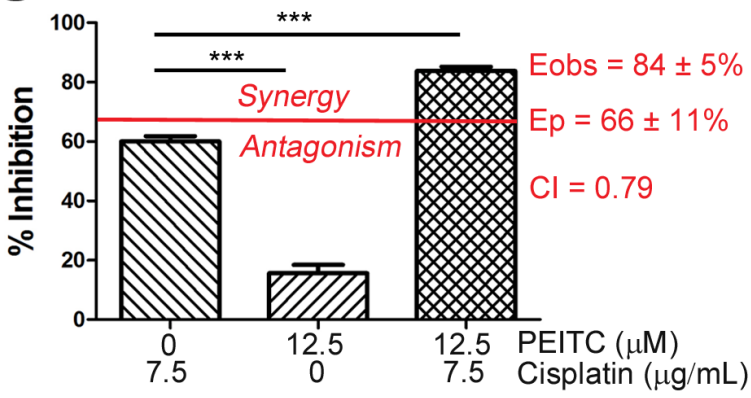

D

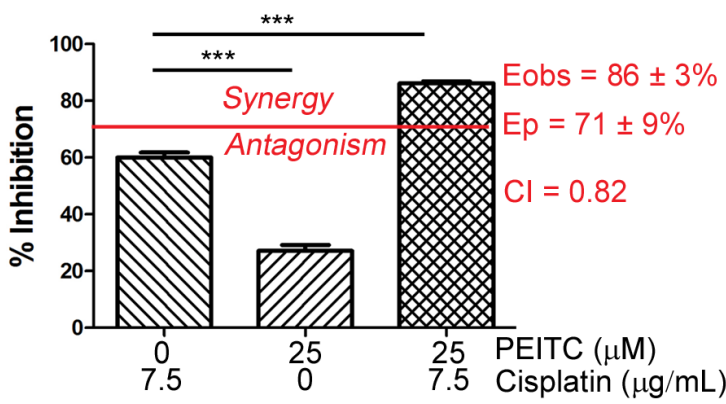

E
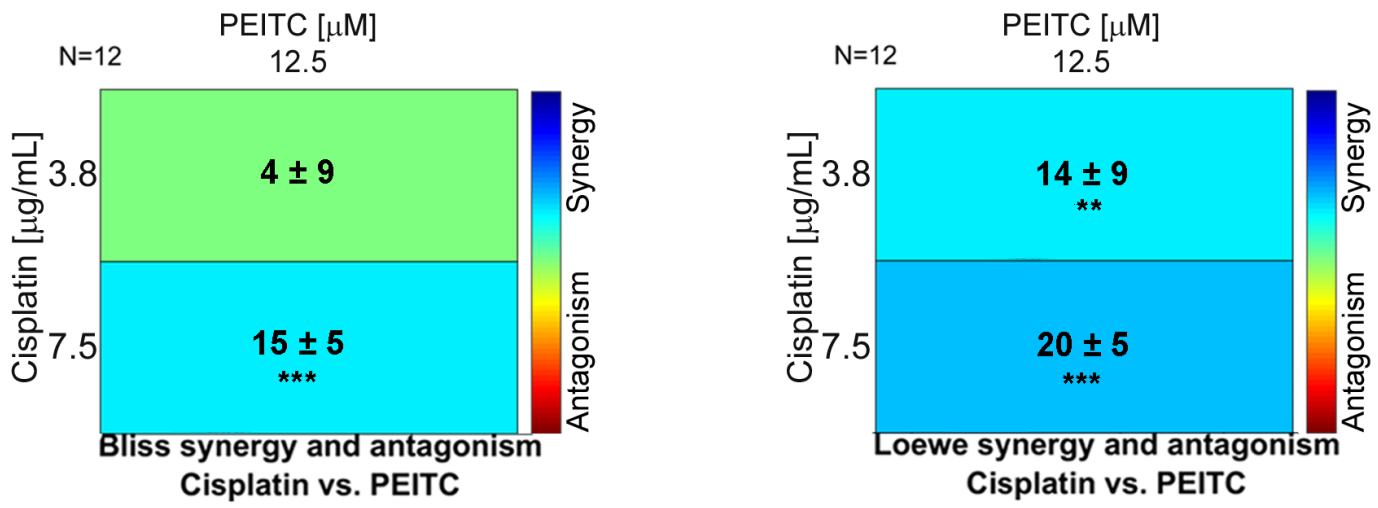

Figure 5: PEITC exerts a synergistic effect on the cisplatin-induced reduction of MCF-7 cell viability. (A) HEK293T cells were incubated with PEITC $(15 \mu \mathrm{M})$, ML323 $(30 \mu \mathrm{M})$ or with DMSO (vehicle only) in the presence and absence of hydroxyurea (2.5 mM) for $3 \mathrm{~h}$. Whole cell lysates were analyzed by SDS-PAGE and western blot. (B) MCF-7 cells were incubated with PEITC, cisplatin or with a 1:1 combination of PEITC and cisplatin for $48 \mathrm{~h}$. Cell viability was measured using the CCK-8 assay. Data represent quadruplicate samples of at least 3 independent experiments $(\mathrm{n} \geq 12$ ). (C-D) MCF-7 cells were treated with 12 or $25 \mu \mathrm{M}$ PEITC in combination with $7.5 \mu \mathrm{g} / \mathrm{mL}$ cisplatin for $48 \mathrm{~h}$. Inhibition of cell growth/viability was measured using the CCK-8 assay and CI values were determined using the Bliss independence model as described in Materials and Methods. Data represent quadruplicate samples from 3 independent experiments $(\mathrm{n}=$ 12). (E). As in (C), drug interaction was analyzed using Combenefit. Data represent quadruplicate samples from 3 independent experiments $(\mathrm{n}=12)$. 'ns' denotes not significant. $* \mathrm{p}<0.05$; ** $\mathrm{p}<0.01$; *** $\mathrm{p}<0.001$. 

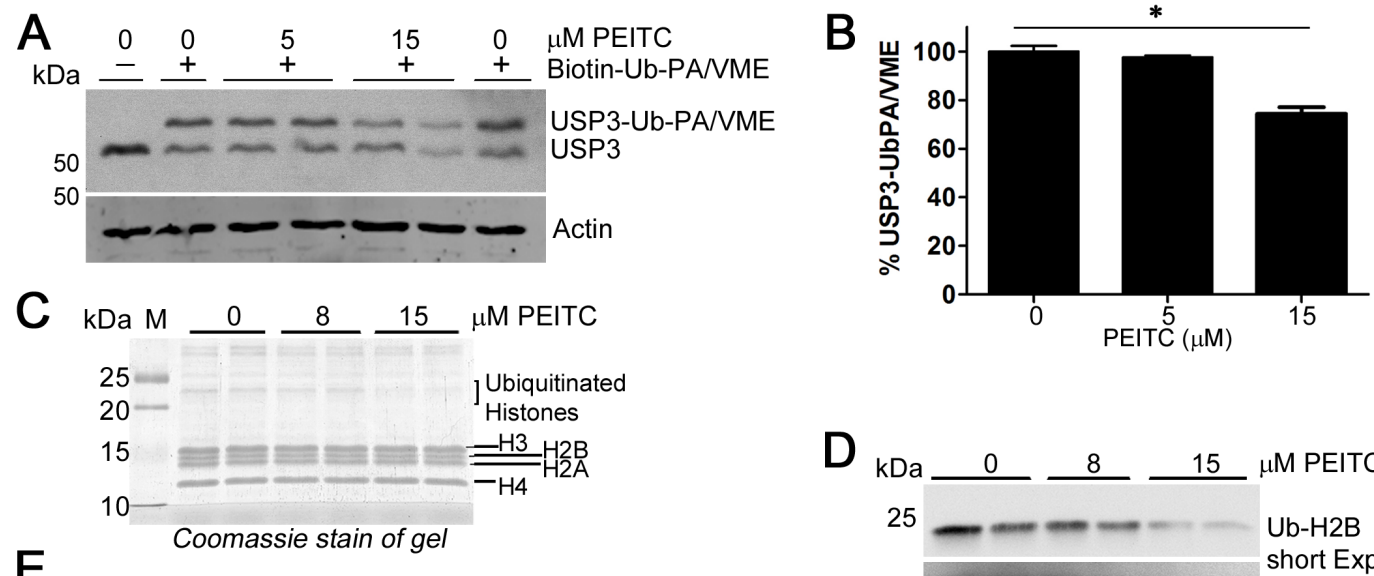

$\mathrm{E}$
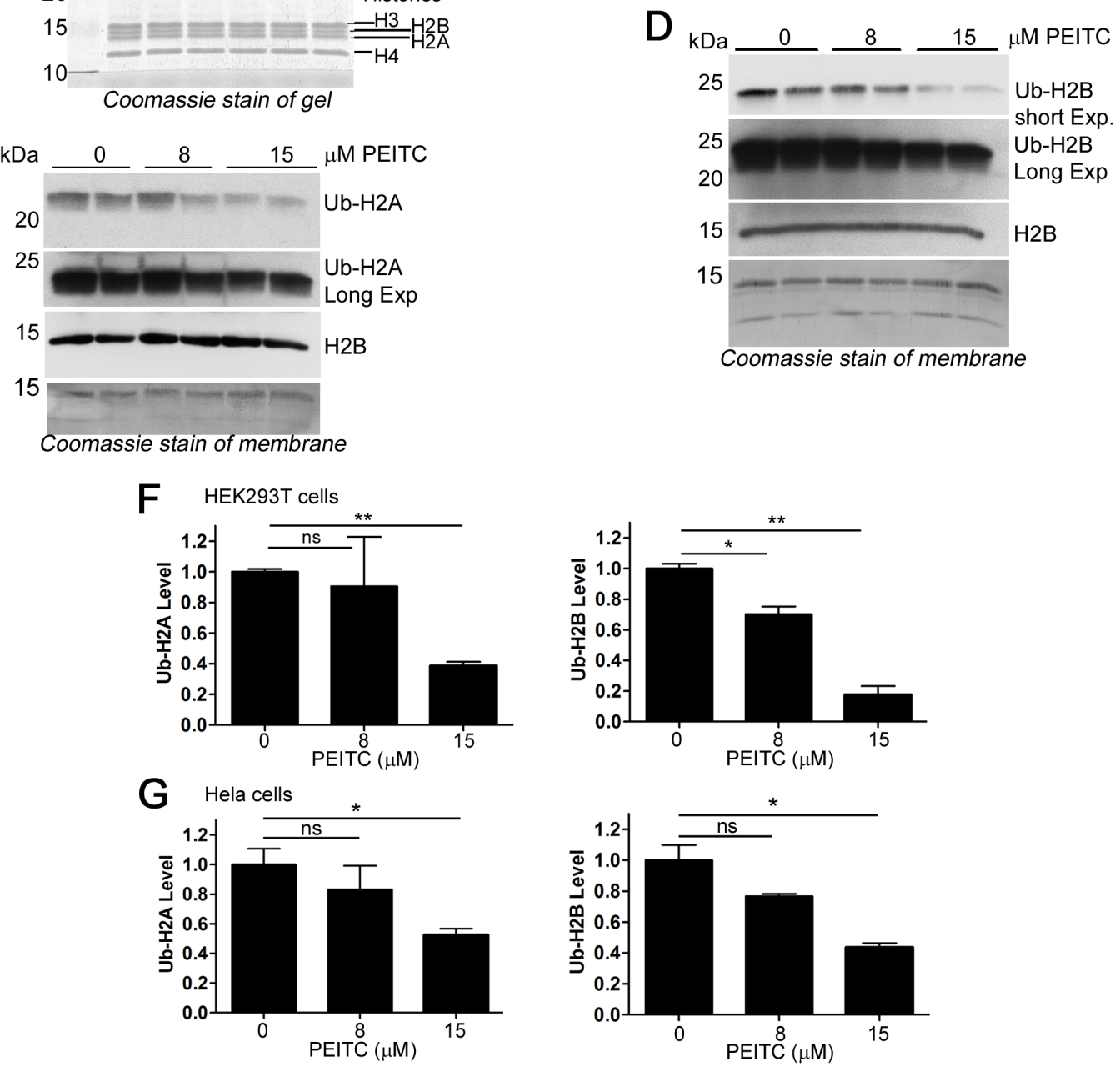

Figure 6: PEITC inhibits histone $\mathrm{H} 2 \mathrm{~A}$ and $\mathrm{H} 2 \mathrm{~B}$ deubiquitinases, yet reduces levels of ubiquitinated $\mathrm{H} 2 \mathrm{~A}$ and $\mathrm{H} 2 \mathrm{~B}$. (A) HEK293T cells were incubated with PEITC for $3 \mathrm{~h}$, harvested, washed and lysed with glass beads. Clarified lysates adjusted to $1.6 \mathrm{mg} / \mathrm{mL}$ and treated with Biotin-Ub-PA/VME $\left(1.2 \mu \mathrm{M}\right.$, an equal mix of both probes) for $8 \mathrm{~min}$ at $25^{\circ} \mathrm{C}$ and analyzed by SDS-PAGE and western blot. Actin shown as loading control. (B) Clarified lysates were prepared as in (A) and \% USP3-Ub-PA/VME was determined (densitometry) by calculating the ratio of the top, USP3-probe conjugated band to total USP3 levels. Data were normalized to the DMSO (vehicle only) control. Data represent mean \pm SD of 2 independent experiments. Representative blot shown in (A) (C-E) HEK293T cells were incubated with PEITC or with DMSO (vehicle only) for $3 \mathrm{~h}$. Cells were harvested and subjected to standard histone extraction protocol. (C) An equal volume of histone extract from each experiment was resolved on a 14\% polyacrylamide gel and stained with InstantBlue (Expedeon). (D) and (E) Histone extracts (equal protein load for each lane) were analyzed by SDS-PAGE and immunoblotted with anti-ubiquityl-H2A, anti-ubiquityl-H2B, or with anti-H2B. Data are representative of two independent experiments. Coomassie stain of membrane shown to demonstrate loading. (F) Quantification (densitometry) of blots shown in (D) and (E), Ub-H2A and Ub-H2B protein levels were normalized to total histone levels (from Coomassie stained membrane). Data represent mean \pm range of two independent experiments. (G) HeLa cells were incubated with PEITC or with DMSO (vehicle only) for $3 \mathrm{~h}$. Cells were harvested and subjected to standard histone extraction protocol. Ub-H2A and Ub-H2B protein levels were normalized to total histone levels (from Coomassie or Ponceau S stained membrane). Data represent mean $\pm \mathrm{SD}$ of two independent experiments. Representative blots and stains shown in Supplementary Figure 5. 'ns' equals not significant. $\mathrm{p}<0.05 * ; \mathrm{p}<0.01 * * ; \mathrm{p}<0.001 * * *$. 

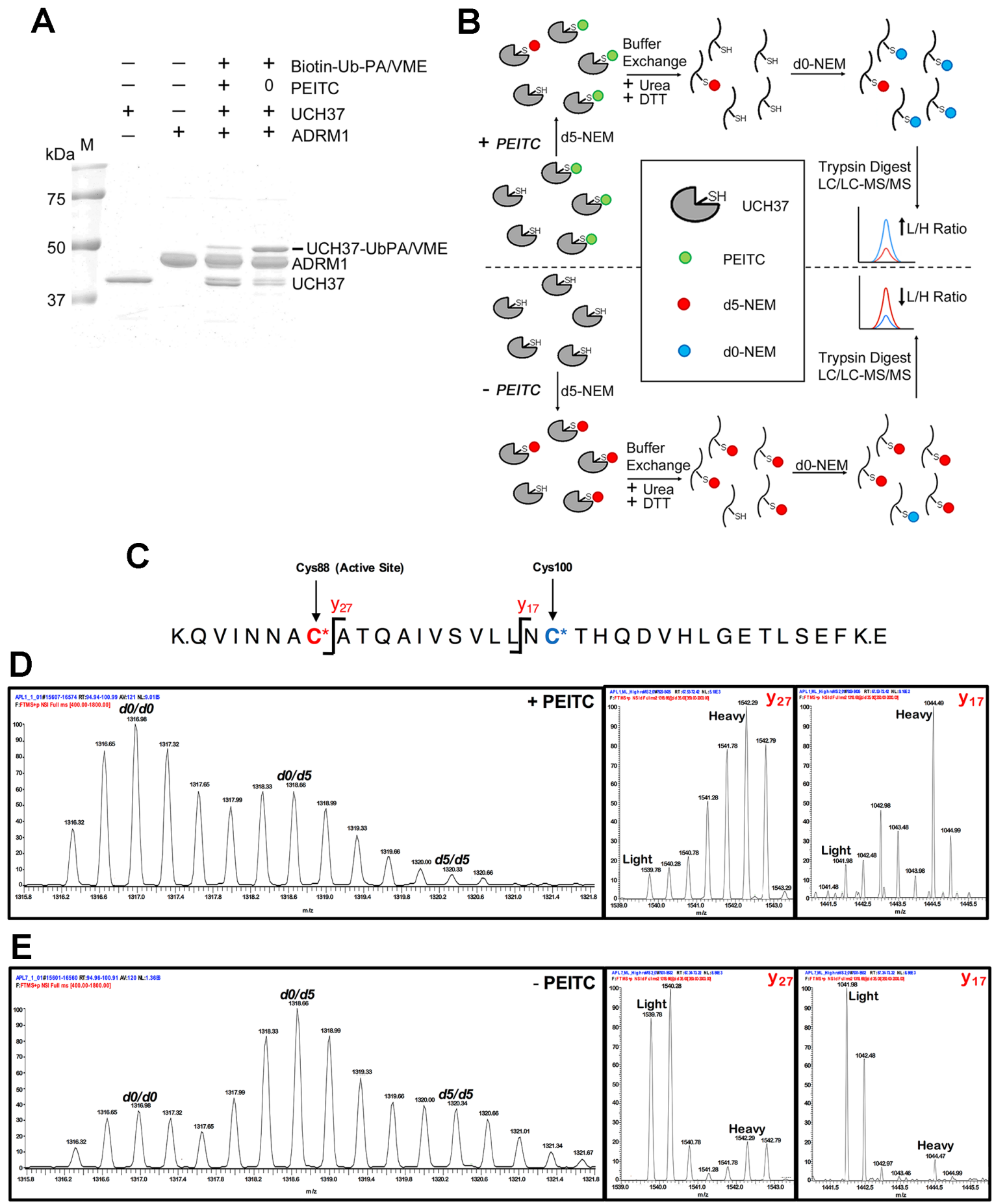

Figure 7: PEITC targets the catalystic cysteine in UCH37. (A) rUCH37/ADRM1 complex (1:1.3 molar ratio) was incubated with $1.5 \mathrm{mM}$ PEITC for $15 \mathrm{~min}$ at $25^{\circ} \mathrm{C}$ and then treated with Biotin-Ub-PA/VME (an equal mix of both probes) for $5 \mathrm{~min}$ at $25^{\circ} \mathrm{C}$. Coomassie stain of gel depicted. (B) Strategy for identifying PEITC labeled UCH37 cysteines. Samples (+/- PEITC) are initially treated with deuterated N-ethylmaleimide (d5-NEM), then denatured in the presence of dithiothreitol (DTT) to reverse the PEITC modification. Samples are then treated with unlabeled d0-NEM to label newly exposed cysteines and subjected to trypsin digestion. The resulting peptide samples are analyzed by LC-MS/MS. Peptides containing cysteine residues that were modified by PEITC will have a higher ratio of d0-NEM/d5NEM labeled peptides compared to cysteine residues that did not form a PEITC adduct. (C) Schematic of the tryptic peptide containing the UCH37 active site cysteine residue. The active site cysteine (Cys88) is highlighted in red, while the second non-active site cysteine (Cys100) is highlighted in blue. The y17 and y27 ions fragmentation sites are also indicated. (D) MS1 and MS2 analysis of the C88/C100 tryptic peptide from the PEITC treated sample. Averaged d0/d0, d0/d5, and d5/d5 isotopic envelopes are displayed as well as the y17 and y27 fragmentation ions for the d0/d5 parent ion. (E) MS1 and MS2 analysis of the Cys88/Cys100 tryptic peptide from the untreated sample. Averaged $\mathrm{d} 0 / \mathrm{d} 0, \mathrm{~d} 0 / \mathrm{d} 5$, and $\mathrm{d} 5 / \mathrm{d} 5$ isotopic envelopes are displayed as well as the $\mathrm{y} 17$ and $\mathrm{y} 27$ fragmentation ions for the $\mathrm{d} 0 / \mathrm{d} 5 \mathrm{parent}$ ion. 
to quantify PEITC occupancy of the active-site Cys88 using differential isotopic labeling of cysteines in the presence and absence of PEITC. Briefly, UCH37 samples (+/-PEITC) were treated with isotopically heavy $N$-ethyl maleimide (d5-NEM) to cap all exposed and reactive cysteine residues (Figure 7B). After UCH37 denaturation and treatment with DTT, any newly exposed cysteines were then capped with isotopically light NEM (d0-NEM). High-resolution MS analysis was used to quantify the light versus heavy intensities for each cysteine-containing peptide. A cysteine targeted by PEITC would be expected to display an increase in the $\mathrm{d} 0$-species and a decrease in the $\mathrm{d} 5$-species relative to the untreated sample. However, analysis of the active-site Cys 88 was complicated by the presence of a second cysteine residue (Cys100) on the same peptide, affording three potential NEM adducts (d5/ $\mathrm{d} 5, \mathrm{~d} 0 / \mathrm{d} 5$ and $\mathrm{d} 0 / \mathrm{d} 0$ ) (Figure 7C). An increase in the $\mathrm{d} 0 / \mathrm{d} 5$ and the $\mathrm{d} 0 / \mathrm{d} 0$ species in the +PEITC sample is observed relative to the -PEITC sample, indicating that PEITC targets one or both of these two cysteine residues (Figure $7 \mathrm{D}$ and $7 \mathrm{E}$ ). To assign the site of $\mathrm{d} 0$-NEM labeling, the fragmentation (MS/MS) spectra were analyzed for fragments that contained d0 versus d5 NEM. Specifically, for the two fragment ions that contain Cys100 but not Cys88 (y17 and y27), the predominant species in the +PEITC sample contains the d5-NEM labeling on Cys100 (Figure 7D and 7E). Therefore, treatment with PEITC results in an increase in d0-NEM labeling at Cys88, indicating that the active-site cysteine is the site of PEITC modification.

\section{DISCUSSION}

Dietary ITCs such as PEITC have well-established anticancer activities and numerous potential targets of ITCs have been identified [2-4, 6]. Nonetheless, the molecular mechanisms of ITC action are poorly understood. Clearly understanding the molecular basis of ITC action is important for identifying the diseases that would most benefit from treatment.

DUBs regulate processes considered critical hallmarks of cancer such as cell proliferation, angiogenesis and apoptosis. Our work demonstrates that PEITC is a broad spectrum DUB inhibitor at physiologically relevant concentrations [23]. We previously identified two DUB targets of PEITC, UCH37 and USP9x. The inhibition of USP9x accounts for the PEITC-induced decreases in the oncoproteins MCL1 and Bcr-Abl. Here we identify 9 additional PEITC-sensitive DUBs, which can explain many cellular effects of PEITC (Table 1). Chief among these is the ability of PEITC to sensitize cancer cells to cisplatin, and reverse cisplatin resistance [12-15]. Cisplatin crosslinks DNA, and mechanisms of resistance include increased DNA repair as well as enhanced tolerance of DNA damage [60]. Seven PEITCsensitive DUBs have well-recognized roles in DNA repair or chromatin remodeling, including USP1, USP3, USP10, USP11, USP16, USP22 and UCH37. This polypharmacology is in keeping with the complicated relationship between cisplatin and PEITC action observed in our experiments, with synergism observed at low concentrations and antagonism observed at high concentrations. The synergistic interaction, at least in MCF-7 cells under the conditions of our experiments, requires higher concentrations of PEITC than obtained from dietary consumption, but is in the range of the concentrations used in drug trials.

USP1 has garnered increasing attention as an attractive therapeutic target [38, 39, 41, 42]. USP1 expression is upregulated in several cancers [37] and its dysregulation has been linked to cisplatin-resistance both in non-small cell lung cancer and osteosarcoma cells $[39,61]$. USP1 over-expression is associated with cancer aggressiveness in multiple tumor types [40, 62, 63]. The USP1-selective inhibitor ML323 sensitizes cancer cells to cisplatin, demonstrating that USP1 inhibition is sufficient to explain the effects of PETIC. PEITC is more effective than ML323 as judged by accumulation of Ub-PCNA, possibly because it both inhibits USP1 and decreases USP1 levels (note that both the accumulation of Ub-PCNA and the knockdown of USP1 are also new activities for PEITC). Our experiments indicate that PEITC increases the ubiquitination and subsequent degradation of USP1 by the proteasome. USP1 is targeted for proteasomal degradation by the multi-subunit E3 ligase, APC/C $\mathrm{C}^{\mathrm{Cdh} 1}$ in a cell cycle dependent manner [64], so perhaps the decrease in USP1 is a consequence of the ability of PEITC to cause cell cycle arrest $[2,65]$. Alternatively, USP1 may be protected from degradation by another PEITC-sensitive DUB.

While USP1 inhibition is sufficient to account for the ability of PEITC to sensitize cells to cisplatin, the other inhibited DUBs are also likely to play important roles. The decrease in mono-Ub-H2A and -H2B, another new PEITC activity revealed in the current work, will also promote cisplatin sensitivity. Both histones play important roles in the epigenetic control of gene expression, cell cycle progression, and DNA damage repair [33, 66], functions that are all perturbed by PEITC treatment. Histone deubiquitination alters chromatin structure and limits access of DNA repair proteins to damaged sites, thus sensitizing cells to cisplatin [58]. Proteasome inhibitors also reduce mono-Ub-H2A and $-\mathrm{H} 2 \mathrm{~B}$ and sensitize cells to cisplatin $[58,67]$, as does another broadspectrum DUB inhibitor [55]. All of these agents cause the accumulation of poly-ubiquitinated proteins, and the consequent depletion of free $\mathrm{Ub}$ causes a re-distribution of $\mathrm{Ub}$ from the nucleus to the cytosol that results in the de-ubiquitination of histones $\mathrm{H} 2 \mathrm{~A}$ and H2B [67].

Our SILAC experiments also provide possible explanations for other previously described PEITC activities and suggest new PEITC activities. The PEITC- 
induced decrease in ID2 and ID3 can be attributed to the inhibition/knockdown of USP1 [24, 40]. ID proteins are transcriptional regulators required for the maintenance of cancer stem cells. In addition, ID proteins are implicated in tumor angiogenesis and induce expression of pro-angiogenic factors including hypoxia-inducible factor-1 $\alpha$ (HIF1 $\alpha$ ), vascular endothelial growth factor A (VEGFA), interleukin-6 (IL-6) [40, 68]. Interestingly, PEITC treatment lowers levels of each of these angiogenic proteins [69-71]. The ability of PEITC to reduce the levels of mutant p53 levels may be attributed to the inhibition of USP10 [72]. Moreover, while the cellular functions of USP48 are not well defined, it controls the proteosomedependent turnover of activated NF- $\kappa \mathrm{B} / \mathrm{RelA}$ in the nucleus, and thus regulates inflammatory and immune response. Depletion of USP48 decreases NF- $\kappa$ B target gene expression [73]. Thus inhibition of USP48 can explain how PEITC reduces the inflammatory response and the associated markers iNOS, TNF- $\alpha$ and IL-6 [74, 75]. USP 22 is a member of the 11-gene 'death-fromcancer' signature that predicts cancer aggressiveness and the likelihood of treatment failure in a wide range of malignancies [76-79]. USP22 is a subunit of the human SAGA (hSAGA) transcriptional regulation complex and contributes to cancer 'stemness' by activating a range of genes. USP22 deubiquitinates other substrates; it stabilizes COX-2 [80] and it trims K63-linked polyubiquitin from transcriptional regulator FBP1 [81], a requirement for FBP1-mediated repression of the cell-cycle inhibitor $\mathrm{p} 21^{\mathrm{WAF} 1}$. Thus inhibition of USP22 can explain the mechanisms underlying PEITCs ability to both increase p2 $1^{\mathrm{WAF} 1}$ levels $[82,83]$ and decrease levels of COX-2 [71, 84]. VCPIP1 (also known as VCIP135) has specificity for K11 and K48 linkages and is involved in p97/p47mediated processes [85]. VCPIP1 is required for the reassembly of Golgi stacks after mitosis [86]. These observations suggest that PEITC will also perturb these processes. Lastly, PEITC-downregulated proteins are attractive substrate candidates for the uncharacterized DUB USP40. It is very likely that the promiscuous inhibition of DUBs, and the resulting pleiotropic effects, is an important factor in the anticancer activity of PEITC. Indeed, the importance of such polypharmacology in drug efficacy is increasingly recognized [87].

Cruciferous vegetables and dietary ITCs are in more than a dozen clinical trials for various cancers including lung, oral, prostate, melanoma, breast, and pancreatic. Trials are also underway to investigate the effects of ITCs on inflammation and the immune response. Understanding the mechanism of action of ITCs should facilitate their use in the clinic and may also lead to the discovery of novel DUB-substrate interactions, new therapeutic targets, and the development of more potent and selective DUB inhibitors.

\section{MATERIALS AND METHODS}

\section{Reagents}

All chemicals and reagents were from Sigma Aldrich unless otherwise stated. Solvents (except DMSO) were from Fisher (Pittsburg, PA). Other reagents used in this study: PEITC (Acros Organics); Bortezomib (Millennium Pharmaceuticals); Mini-Complete and PhosSTOP inhibitory cocktails (Roche Applied Science); recombinant human K63-linked di-ubiquitin (UC-300), recombinant human $\mathrm{His}_{6}-\mathrm{USP} 1 / \mathrm{UAF} 1$ complex (E-568; Boston Biochem.); DMEM, glutamax, penicillin/streptomycin (Gibco); trypsin (0.25\%), DPBS (Hyclone); cell dissociation buffer (fisher); Bradford dye (Bio-rad); dithiothreitol (GoldBio Tech); PVDF hybond, Amersham ECL Prime WB detection reagent (GE Healthcare Life Sciences); Blue Biofilm (Denville Scientific); ML323 USP1 inhibitor (EMD Millipore); TransIT 2020 transfection reagent (Mirus bio); Pierce protein $\mathrm{G}$ magnetic beads (ThermoFisher Scientific); TAMRA-ubiquitin propargylamide (TAMRA-Ub-PA), Cy5-ubiquitin vinyl methyl ester (Cy5-Ub-VME), Biotin-Ahx-Ub-VME, Biotin-Ahx-Ub-PA and UbRh110MP (UbiQ). HA-ubiquitin vinylsulfone (HA-UbVS) and HA-Ub-VME were synthesized using standard methods previously described [88]. The plasmid encoding the HA-Ub(1-75)-intein-chitin binding domain fusion protein was a gift from Prof $\mathrm{H}$. Ploegh of the Whitehead Institute.

\section{Antibodies}

The following antibodies were used: anti-K48linked ubiquitin, clone APU2 (Millipore); anti-PARP 9542, anti-USP1 D37B4, anti-ubiquityl-Histone H2A (Lys119), anti-ubiquityl-histone H2B (Lys 120), anti-histone H2B, goat anti-rabbit IgG (HRP), anti-ADRM1, normal rabbit IgG (Cell Signaling Technologies); anti-actin clone AC40 A3853, anti-GAPDH clone G9295, (Abcam); antiUSP3 (rabbit polyclonal) (GeneTex); anti-pcna PC10, anti-Proteasome $\alpha 3$ clone A-9, anti-Proteasome $\beta 1$ clone D-9, anti-Nrf2 clone A-10 (Santa Cruz); Cy3 conjugated secondary antibodies (GE Life Sciences); anti-UCH37, goat anti-mouse IgG (HRP) (Abcam). IRDye $800 \mathrm{CW}$ donkey anti-rabbit and IRDye680CW donkey anti-mouse were obtained from Li-Cor.

\section{Vehicle}

All compounds were dissolved in DMSO and further diluted with culture medium before use for tissue culture assays (final DMSO concentrations were less than $0.1 \%$ ). For in vitro assays, the final DMSO concentration was $1 \%$. 


\section{Tissue culture assays and western blot}

HeLa (ATCC, purchased June, 2015), MCF-7 and HEK293T cells (ATCC, each authenticated June 2015, 9-marker STR, IDEXX BioResearch) were cultivated in DMEM supplemented with $10 \%$ heat inactivated FBS, 1X glutamax, and $1 \mathrm{X}$ penicillin/streptomycin under standard conditions $\left(37{ }^{\circ} \mathrm{C}\right.$ in a $5 \% \mathrm{CO}_{2}$ humidified atmosphere). All active cell cultures routinely tested for presence of Mycoplasma (MycoAlert ${ }^{\mathrm{TM}}$ detection kit, Lonza) and confirmed to be Mycoplasma free.

Whole cells lysates (WCLs) for immunoblots were prepared according standard protocol. Protein concentration was determined using Bradford assay with IgG as standard. For acid extraction of histones, cells were lysed in TEB buffer (phosphate buffered saline containing $0.5 \%$ Triton X-100) containing $1 \mathrm{x}$ protease inhibitor cocktail and insoluble pellets were resuspended in $0.2 \mathrm{M} \mathrm{HCl}$ and incubated overnight at $4^{\circ} \mathrm{C}$; the acid was neutralized with $1 \mathrm{M}$ Tris- $\mathrm{HCl}(\mathrm{pH} 8.5)$ for Western blot analysis. Proteins were resolved by SDS-PAGE, transferred onto PVDF membranes and immunoblotted with the appropriate antibody. Signals were visualized with HRP-conjugated secondary antibodies and ECL Prime reagent (Amersham GE). In certain cases, signals were visualized with $\mathrm{Cy} 3$-conjugated secondary antibodies (scanned on GE Typhoon scanner) or with IRDye800CW or IRDye680CW (scanned on Licor scanner). Densitometry was performed with ImageJ software (http:// rsbweb.nih.gov/ij/download.html).

\section{PEITC inhibitor selectivity as determined by quantitative mass spectrometry}

HeLa cells were grown in DMEM media minus L-lysine and L-arginine (Thermo Scientific Pierce) supplemented with $10 \%$ dialyzed FBS for SILAC (Pierce), 1x glutaMax (Gibco), 1\% penicillin/streptomycin (Gibco) and either $84 \mu \mathrm{g} / \mathrm{mL}[13 \mathrm{C} / 15 \mathrm{~N}]-\mathrm{L}$-arginine (R10) and $146 \mu \mathrm{g} / \mathrm{mL}\left[{ }^{13} \mathrm{C} /{ }^{15} \mathrm{~N}\right]-\mathrm{L}$-Lysine (K8) (Cambridge Isotope Laboratories) or $84 \mu \mathrm{g} / \mathrm{mL}$ L-arginine (R0) and $146 \mu \mathrm{g} /$ $\mathrm{mL}$ L-lysine (K0) (Sigma) at $37^{\circ} \mathrm{C}$ and $5 \% \mathrm{CO}_{2}$ for a minimum of 6 passages (complete metabolic labeling of proteome confirmed by MS). Heavy labeled or unlabeled HeLa cells were lysed with glass beads in DUB buffer and protein concentration adjusted to $1.4 \mathrm{mg} / \mathrm{mL}$. Heavy lysates were incubated with PEITC $(75 \mu \mathrm{M})$ and light lysates with DMSO (vehicle only, 1\%) for $25 \mathrm{~min}$ at $37^{\circ} \mathrm{C}$ at which time Biotin-Ahx-Ub-VME/PA (equal mix of both biotin probes) was added. The mixtures were incubated a further $30 \mathrm{~min}$ at $37^{\circ} \mathrm{C}$ and then diluted 5 -fold into ice cold DUB buffer. Excess probe was removed by filtration (30K amicon filter) and the combined concentrated lysate ( 8.4 $\mathrm{mg}$ total protein) was stored at $-80^{\circ} \mathrm{C}$ until streptavidin enrichment and MS analysis. A double control also was performed where both the unlabeled and the heavy labeled lysates were incubated with DMSO (1\%, vehicle) only prior to addition of Biotin-labeled probe as above. Probe-labeled and control samples were heated at $80^{\circ} \mathrm{C}$ in $1.2 \% \mathrm{SDS} / \mathrm{PBS}$ for $5 \mathrm{~min}$, diluted to $0.2 \% \mathrm{SDS} / \mathrm{PBS}$ and added to $100 \mu \mathrm{L}$ of streptavidin-agarose beads (Thermo Scientific). The samples were rotated at room temperature for $3 \mathrm{~h}$, and the beads washed with $0.2 \%$ SDS/PBS, $3 \mathrm{x}$ PBS and $3 x$ water. The washed beads were resuspended in $6 \mathrm{M}$ urea/PBS, treated with $10 \mathrm{mM}$ dithiothreitol (DTT) $\left(15 \mathrm{~min}, 65^{\circ} \mathrm{C}\right)$ and $20 \mathrm{mM}$ iodoacetamide (room temperature, dark, $30 \mathrm{~min}$ ), and diluted to $2 \mathrm{M}$ urea/ PBS. On-bead trypsin digestion was performed using 2 $\mu \mathrm{g}$ of sequencing-grade trypsin (Promega) overnight at $37^{\circ} \mathrm{C}$. LC/LC-MS/MS analysis was performed on an LTQ Orbitrap Discovery mass spectrometer (ThermoFisher) coupled to an Agilent 1200 series HPLC. Digests were pressure loaded onto a $250 \mu \mathrm{m}$ fused silica desalting column packed with $4 \mathrm{~cm}$ of Aqua $\mathrm{C} 18$ reverse phase resin (Phenomenex). The peptides were eluted onto a biphasic column $(100 \mu \mathrm{m}$ fused silica with a $5 \mu \mathrm{m}$ tip, packed with $10 \mathrm{~cm} \mathrm{C} 18$ and $3 \mathrm{~cm}$ Partisphere strong cation exchange resin (SCX, Whatman)) using a gradient 5-100\% Buffer B in Buffer A (Buffer A: 95\% water, 5\% acetonitrile, 0.1\% formic acid; Buffer B: $20 \%$ water, $80 \%$ acetonitrile, $0.1 \%$ formic acid). The peptides were eluted from the SCX onto the $\mathrm{C} 18$ resin and into the mass spectrometer following the four salt steps outlined in Weerapana et al [89]. The flow rate through the column was set to $\sim 0.25 \mu \mathrm{L} \mathrm{min}^{-1}$ and the spray voltage was set to $2.75 \mathrm{kV}$. One full MS scan (400$1800 \mathrm{MW}$ ) was followed by 8 data dependent scans of the nth most intense ions with dynamic exclusion enabled. The generated tandem MS data from each sample was searched using the SEQUEST algorithm against the human UniProt database. Data sets were searched independently with the following parameter files; for the light search, all amino acids were left at default masses; for the heavy search, static modifications on lysine $(+8.0142 \mathrm{~m} / \mathrm{z})$ and arginine $(+10.0082 \mathrm{~m} / \mathrm{z})$ were specified. A static modification of +57 on Cys was specified on all searches to account for iodoacetamide alkylation. The SEQUEST output files generated from the digests were filtered using DTASelect 2.0. Reported peptides were required to be fully tryptic and discriminant analyses were performed to achieve a peptide false-discovery rate below $5 \%$. SILAC-assisted MS data represent two completely independent biological replicates. Quantification of light/heavy ratios " $R$ " was performed using the CIMAGE quantification package as described previously [90]. CIMAGE reports peptide $\mathrm{L} / \mathrm{H}$ ratios for each unique peptide by both MudPIT run and charge state. These peptides are grouped by protein (Supplementary Table 2) and the median (or average of the two median values for an even number of ratios) peptide $\mathrm{L} / \mathrm{H}$ ratio is chosen as the representative $\mathrm{L} / \mathrm{H}$ ratio for that protein. Median values are used instead of averages in order to better filter out outlier peptide ratios. SILACassisted MS data represent two completely independent 
biological replicates (Supplementary Table 1). A number of parameters were used to identify significant PEITC induced changes in protein $\mathrm{L} / \mathrm{H}$ ratio over control samples. First, the average L/H of two biological runs had to be greater than 4 . Second, the $\mathrm{L} / \mathrm{H}$ ratio had to have a statistically significant $p$ value $(p<0.05)$ between treated and untreated samples. Third, at least 5 unique tryptic peptides had to have been identified with valid ratios for that protein (Supplementary Table 2).

\section{Activity profiling}

Cell pellets were typically stored at $-80{ }^{\circ} \mathrm{C}$ until required, at which time they were thawed on ice. Cell lysis was performed in DUB buffer (50 mM K $\mathrm{HPO}_{4}$, $\mathrm{pH} 7.5,150 \mathrm{mM} \mathrm{NaCl}, 0.5 \mathrm{mM}$ BME) using a Dounce homogenizer (10 strokes, with grinding, on ice) or by glass beads (as indicated). Lysate (1.5-2 $\mathrm{mg} / \mathrm{mL}$ ) was treated with PEITC (or 1\% DMSO control) for 15-25 min, then treated with tagged ubiquitin probe $(200 \mathrm{nM}-1.2$ $\mu \mathrm{M})$. Aliquots were quenched in reducing (dithiothreitol) loading buffer. When required, membranes were stripped in $100 \mathrm{mM}$ glycine, $\mathrm{pH}$ 4, $500 \mathrm{mM} \mathrm{NaCl}, 1 \% \mathrm{SDS}, 5 \mathrm{mM}$ $\mathrm{BME}$, at $50^{\circ} \mathrm{C}$ for $20 \mathrm{~min}$. For all tagged-ubiquitin probe experiments, samples in loading buffer were warmed to 37 ${ }^{\circ} \mathrm{C}$ prior to electrophoresis.

Activity profiling of HEK293T cells was performed by incubating living cells with PEITC (or 0.1\% DMSO control) for $3 \mathrm{~h}$ at $37^{\circ} \mathrm{C}$. Cells were harvested and washed two times with ice cold PBS. Cell pellets were then lysed with glass beads (vortexed, 5 X $3 \mathrm{sec}$ bursts at $4{ }^{\circ} \mathrm{C}$ ) in ice cold lysis buffer ( $50 \mathrm{mM} \mathrm{K}_{2} \mathrm{HPO}_{4}, \mathrm{pH} 7.5,150 \mathrm{mM}$ $\mathrm{NaCl}$ ). The lysate was centrifuged at $17000 \mathrm{~g}$ for $10 \mathrm{~min}$ at $4{ }^{\circ} \mathrm{C}$ and the clarified supernatant (adjusted to $1.5-2 \mathrm{mg} /$ $\mathrm{mL}$ ) was incubated with Cy5-Ub-VME, TAMRA-Ub-PA or with Biotin-Ahx-Ub-VME/PA (equal mix of both biotin probes, $1.2 \mu \mathrm{M}$ ) for $8 \mathrm{~min}$ at $25^{\circ} \mathrm{C}$.

\section{K63-linked di-ubiquitin gel-based assay}

PEITC $(1-90 \mu \mathrm{M})$ was pre-incubated with $150 \mathrm{nM}$ USP1/UAF1 for $8 \mathrm{~min}$ at $37^{\circ} \mathrm{C}$ in assay buffer $(50 \mathrm{mM}$ HEPES, pH 7.7, $0.1 \mathrm{mg} / \mathrm{mL}$ BSA, $0.5 \mathrm{mM}$ EDTA and 0.5 $\mathrm{mM}$ DTT) prior to the addition of K63-linked di-Ub (3 $\mu \mathrm{M})$. After $10 \mathrm{~min}$ at $37^{\circ} \mathrm{C}$, the reaction was quenched by the addition of reducing loading buffer, samples resolved on a $15 \%$ polyacrylamide gel and stained with InstantBlue (Expedeon).

\section{Immunoprecipitations}

For USP1 immunoprecipitations, HEK293T cells were transiently transfected with an expression plasmid for HA-tagged Ubiquitin (HA-Ubiquitin was a gift from Edward Yeh, Addgene plasmid \#18712) using Mirus 2020 according to manufacturer's instructions and confluence at transfection was approximately $60 \%$. $24 \mathrm{~h}$ post- transfection, media was aspirated and replaced with fresh media containing either $0.1 \%$ DMSO or $0.1 \%$ DMSO plus compound and the cells were incubated at $37^{\circ} \mathrm{C}$ for $2 \mathrm{~h}$. The cells were harvested, washed in PBS and re-suspended in lysis buffer [40 mM Tris pH 7.4, $140 \mathrm{mM} \mathrm{NaCl}, 10 \mathrm{mM}$ $\beta$-Glycerophosphate, $1 \mathrm{mM}$ EDTA, 0.1\% CHAPS, 0.5\% NP-40, $50 \mathrm{nM}$ Bortezomib, 1x protease inhibitor cocktail]. After lysis (1x freeze/thaw), protein concentrations were determined (Bradford assay), lysates were adjusted to the same protein concentration $(1 \mathrm{mg} / \mathrm{mL})$ and pre-cleared (400 $\mu \mathrm{L}$ lysate) with $10 \mu \mathrm{L}$ protein $\mathrm{G}$ beads (30 min at 4 ${ }^{\circ} \mathrm{C}$ ). The beads were removed and the cleared lysate was incubated (with rotation) with anti-USP1 or with normal $\mathrm{Rb}$ IgG (negative control) for $2 \mathrm{~h}$ at $4{ }^{\circ} \mathrm{C}$. USP1 was immunoprecipitated with protein $\mathrm{G}$ magnetic beads (15 $\mu \mathrm{L}$ beads rotated at $1 \mathrm{~h}$ at $4{ }^{\circ} \mathrm{C}$. Eluted proteins $(5-12 \mu \mathrm{L}$, identical volumes of eluent) were analyzed by SDS-PAGE and western blot.

\section{MCF-7 proliferation assays}

In viability assays, Cell Counting Kit-8 (CCK8; Dojindo) was used per manufacture's instruction to measure viability following treatment. MCF-7 cells were seeded in each well of a 96-well plate: 5000 cells/well were seeded for $24 \mathrm{~h}$ assays and 3000 cells/well were seeded for $48 \mathrm{~h}$ assays. The cells were then cultured for $24 \mathrm{~h}$ prior to drug treatment. Cisplatin was dissolved in DMEM immediately before use and PEITC was dissolved in DMSO. Cells were then incubated for either $24 \mathrm{~h}$ or $48 \mathrm{~h}$ in $100 \mu \mathrm{L}$ DMEM containing cisplatin, PEITC or a combination of cisplatin and PEITC. $10 \mu \mathrm{L}$ of CCK8 solution was added to each well and incubated for 4 $\mathrm{h}$ at $37^{\circ} \mathrm{C}$. The absorbance of each well at $450 \mathrm{~nm}$ was measured using a microplate reader. Relative viability was measured as a percent of untreated control (DMEM only for cisplatin; DMSO [vehicle only] for PEITC and combination treatments). Concentration-response curves were fitted using a log (agonist) versus response - variable slope equation (See Equation 1) using GraphPad Prism which afforded values of $\mathrm{EC}_{50}$.

Equation $1 \mathrm{Y}=\operatorname{Abs}($ minimum $)+\operatorname{Abs}(\operatorname{maximum}-$ minimum $) /\left(1+10^{\wedge}\left(\left(\operatorname{LogEC} C_{50}-X\right) * n\right)\right)$

where $\mathrm{X}=\mathrm{Log}$ [inhibitor]; $\mathrm{Y}$ is cell viability in percent relative to the control and $\mathrm{n}$ is the Hill slope.

\section{Assessment of cisplatin and PEITC synergism}

We used the Bliss Model to analyze the effects of PEITC and cisplatin co-treatment [91, 92]. The Combination Index (CI) was calculated according to Equations 2 and 3. Synergism is indicated by a CI of less than 1 , additivity by a CI equal to 1 , and antagonism by a CI greater than 1 .

\footnotetext{
Equation $2 \mathrm{CI}=\mathrm{E}_{\text {predicted }} / \mathrm{E}_{\mathrm{Combo}}$$$
\text { Equation } 3 \mathrm{E}_{\text {predicted }}=\mathrm{E}_{\text {cis }}+\mathrm{E}_{\mathrm{PE}}-\left(\mathrm{E}_{\mathrm{cis}} \mathrm{E}_{\mathrm{PE}}\right)
$$ 
where $\mathrm{E}_{\mathrm{cis}}$ is the effect of cisplatin (\% inhibition), $\mathrm{E}_{\mathrm{PE}}$ is the effect of PEITC (\% inhibition) and $\mathrm{E}_{\text {Combo }}$ is the effect of the combined treatment ( $\%$ inhibition).

Co-treatment also was analyzed using Combenefit software, which assesses the Bliss model and two additional classic drug interaction models, the Loewe and the Highest Single Agent (HSA) models [51].

\section{His-UCH37 and His-ADRM1 synthesis and purification}

Human Adrm1 with an N-terminal 10x histidine tag (addgene plasmid 19423 [59]) was expressed in Rosetta2 BL21(DE3) Escherichia coli in high salt (500 $\mathrm{mM} \mathrm{NaCl})$ media containing $0.5 \%$ glycerol (to limit formation of inclusion bodies). Cultures were induced at an $\mathrm{OD}_{600}$ of 0.6 with $0.2 \mathrm{mM}$ IPTG and incubated overnight at $20^{\circ} \mathrm{C}$. Human UCH37 (isoform 1) with an N-terminal 6x histidine tag (addgene plasmid 61929 [93]) was expressed in Rosetta BL21(DE3) Escherichia coli, induced at an $\mathrm{OD}_{600}$ of 0.6 with $0.4 \mathrm{mM}$ IPTG and incubated $2.5 \mathrm{~h}$ at $37^{\circ} \mathrm{C}$. Cultures were harvested by centrifugation and pellets were resuspended in lysis/wash buffer $(20 \mathrm{mM}$ Hepes, Ph 7.6, $200 \mathrm{mM} \mathrm{NaCl}, 30 \mathrm{mM}$ imidazole [IM], 5 $\mathrm{mM}$ TCEP, 5\% glycerol), sonicated and lysates clarified by centrifugation. Clarified lysate was incubated with Ni-NTA resin (McLab) overnight at $4^{\circ} \mathrm{C}$ and His-tagged proteins were eluted by gradient elution with increasing concentrations of IM. Eluted proteins were dialyzed against $20 \mathrm{mM}$ Hepes pH 7.2, $150 \mathrm{mM} \mathrm{NaCl}, 5 \mathrm{mM}$ TCEP, $1 \mathrm{mM}$ EDTA, 5\% glycerol overnight at $4{ }^{\circ} \mathrm{C}$ and then against storage buffer (20 mM Hepes pH 7.2, $150 \mathrm{mM}$ $\mathrm{NaCl}, 2 \mathrm{mM}$ DTT, 5\% glycerol). Protein concentration determined by Bradford assay. His-ADRM1 was $\geq 98 \%$ pure by coomassie stain and western blot and His-UCH37 was $\geq 75 \%$ pure by coomassie stain and western blot. Each was used without further purification.

\section{Reversibility of PEITC-induced inhibition of recombinant $\mathrm{UCH} 37$}

PEITC (1.5 mM) or DMSO (vehicle only control) was pre-incubated with $\mathrm{rUCH} 37 / \mathrm{ADRM} 1$ (1:1.3 molar ratio) (20 $\mathrm{nM} \mathrm{UCH37)} \mathrm{for} 15 \mathrm{~min}$ at $37^{\circ} \mathrm{C}$ in assay buffer (25 mM HEPES, $100 \mathrm{mM} \mathrm{NaCl,} 0.5$ mM EDTA, pH 7.4) prior to the addition of Ub-Rho110MP (150 nM). Just before reaction was initialized, $0 \mathrm{mM}$ or $10 \mathrm{mM}$ DTT was added. Hydrolysis of Ub-Rho110MP was monitored at 37 ${ }^{\circ} \mathrm{C}$ for $15 \mathrm{~min}$ by fluorescence (excitation wavelength 492 $\mathrm{nm}$, emission wavelength $525 \mathrm{~nm}$ ).

\section{PEITC-UCH37 adduct as determined by mass spectrometry}

UCH37 and ADRM1 were mixed in a 1:1.3 molar ratio in assay buffer $(25 \mathrm{mM}$ Hepes $\mathrm{pH} 7.4,100 \mathrm{mM}$
$\mathrm{NaCl}, 0.5 \mathrm{mM}$ EDTA. $0.5 \mathrm{mM}$ DTT) and incubated (5 $\mu \mathrm{M}$ UCH37) with $1.5 \mathrm{mM}$ PEITC or with DMSO (vehicle only, control) at $25^{\circ} \mathrm{C}$ for $2 \mathrm{~h}$ at which time samples were frozen and stored at minus $80{ }^{\circ} \mathrm{C}$ until MS analysis. For quantitative NEM labeling, $100 \mu \mathrm{L}$ of $5 \mu \mathrm{M}(\sim 25$ $\mu \mathrm{g}$ ) UCH37 (plus or minus PEITC) was incubated with $12.5 \mathrm{mM}$ d5-NEM (Cambridge Isotope Laboratories) for $30 \mathrm{~min}$ at $25^{\circ} \mathrm{C}$. UCH37 samples were then buffer exchanged into PBS buffer using a Micro Bio-Spin 30 chromatography column (Bio-Rad), in order to remove unreacted d5-NEM and PEITC. To each samples $5 \mu \mathrm{L}$ of $100 \%$ trichloroacetic acid was added, the samples were vortexed rapidly and frozen at $-80^{\circ} \mathrm{C}$ for 1 hour. The samples were thawed and the precipitated protein was pelleted by centrifugation at $15 \mathrm{k} \mathrm{rpm}$ for 10 minutes. The supernatant was removed and the protein pellets were resuspended in $500 \mu \mathrm{L}$ of ice-cold acetone and pelleted again by centrifugation at $5 \mathrm{k}$ rpm for 10 minutes. Pellets were resuspended in $30 \mu \mathrm{L}$ of $8 \mathrm{M}$ Urea in PBS followed by addition of $70 \mu \mathrm{L}$ of $100 \mathrm{mM}$ ammonium bicarbonate and $1.5 \mu \mathrm{L} 1 \mathrm{M}$ DTT. Samples were incubated at $65^{\circ} \mathrm{C}$ for 15 minutes. To the samples $2.5 \mu \mathrm{L}$ of $500 \mathrm{mM} \mathrm{d0}$ NEM (Sigma-Aldrich) (12.5 mM final concentration) was added and the samples were incubated at room temperature. After 30 minutes, $120 \mu \mathrm{L}$ of PBS was added and the samples were vortexed rapidly. To each sample, 4 $\mu \mathrm{L}$ of $0.5 \mu \mathrm{g} / \mu \mathrm{L}$ trypsin (Promega), and $2.5 \mu \mathrm{L} 100 \mathrm{mM}$ $\mathrm{CaCl}_{2}$ was added and the samples were agitated overnight at $37^{\circ} \mathrm{C} .10 \mu \mathrm{L}$ of formic acid was added to each sample, followed by centrifugation at $15 \mathrm{k} \mathrm{rpm}$ for $20 \mathrm{~min}$ to pellet undigested protein. The supernatant was then transferred to a new tube and stored at $-20^{\circ} \mathrm{C}$ until ready for $\mathrm{MS}$ analysis.

Samples were analyzed by LC-MS/MS on an LTQ Orbitrap XL mass spectrometer (Thermo Fisher) coupled to an EASY-nLC 1000 nanoLC (Thermo Fisher). $10 \mu \mathrm{l}$ of each sample were loaded onto $100 \mu \mathrm{m}$ fused silica column with a $5 \mu \mathrm{m}$ tip packed with $10 \mathrm{~cm}$ of Aqua C18 reversephase resin (Phenomenex) using the EASY-nLC 1000 autosampler. Peptides were eluted with a gradient $0-100 \%$ buffer B in buffer A (buffer A: 95\% water, 5\% acetonitrile, $0.1 \%$ formic acid; buffer $\mathrm{B} ; 20 \%$ water, $80 \%$ acetonitrile, $0.1 \%$ formic acid). The flow rate through the column was set to $400 \mathrm{nl} / \mathrm{min}$ and the spray voltage was set to $3.5 \mathrm{kV}$. One full MS scan (FTMS) (400-1800 MW) was followed by three high resolution data-dependent scans (FTMS) of the nth most intense ion from an imported mass list of the +3 and +4 ions of the active site cysteine containing tryptic peptide $(1316.98,1318.66,1320.34$, 987.99, 989.25, 990.51) with dynamic exclusion disabled. MS1 and MS2 spectra were manually analyzed.

\section{ACKNOWLEDGMENTS}

We gratefully acknowledge Modhurika De for her assistance with western blotting. 


\section{CONFLICTS OF INTEREST}

F. El Oualid has ownership interest in Shares in UbiQ (Bio) company. The other authors have no potential conflicts of interest.

\section{GRANT SUPPORT}

This work was supported by National Institutes of Health grants R01GM100921 (LH) and 1R01GM117004 (EW) and a Brandeis University Sprout award (APL).

\section{REFERENCES}

1. Tang L, Zirpoli GR, Guru K, Moysich KB, Zhang Y, Ambrosone $\mathrm{CB}$, McCann SE. Intake of cruciferous vegetables modifies bladder cancer survival. Cancer Epidemiol Biomarkers Prev. 2010; 19:1806-11.

2. Gupta P, Kim B, Kim SH, Srivastava SK. Molecular targets of isothiocyanates in cancer: recent advances. Mol Nutr Food Res. 2014; 58:1685-707.

3. Cheung KL, Kong AN. Molecular targets of dietary phenethyl isothiocyanate and sulforaphane for cancer chemoprevention. AAPS J. 2010; 12:87-97.

4. Singh SV, Singh K. Cancer chemoprevention with dietary isothiocyanates mature for clinical translational research. Carcinogenesis. 2012; 33:1833-42.

5. Wang D, Upadhyaya B, Liu Y, Knudsen D, Dey M. Phenethyl isothiocyanate upregulates death receptors 4 and 5 and inhibits proliferation in human cancer stem-like cells. BMC Cancer. 2014; 14:591.

6. Gupta P, Wright SE, Kim SH, Srivastava SK. Phenethyl isothiocyanate: A comprehensive review of anti-cancer mechanisms. Biochim Biophys Acta. 2014; 1846:405-24. doi: 10.1016/j.bbcan.2014.08.003.

7. Lin JF, Tsai TF, Liao PC, Lin YH, Lin YC, Chen HE, Chou KY, Hwang TI. Benzyl isothiocyanate induces protective autophagy in human prostate cancer cells via inhibition of mTOR signaling. Carcinogenesis. 2013; 34:406-14.

8. Mi L, Di Pasqua AJ, Chung FL. Proteins as binding targets of isothiocyanates in cancer prevention. Carcinogenesis. $2011 ; 32: 1405-13$.

9. Lee JW, Cho MK. Phenethyl isothiocyanate induced apoptosis via down regulation of $\mathrm{Bcl}-2 / \mathrm{XIAP}$ and triggering of the mitochondrial pathway in MCF-7 cells. Arch Pharm Res. 2008; 31:1604-12.

10. Ji Y, Morris ME. Determination of phenethyl isothiocyanate in human plasma and urine by ammonia derivatization and liquid chromatography-tandem mass spectrometry. Anal Biochem. 2003; 323:39-47.

11. Ji Y, Kuo Y, Morris ME. Pharmacokinetics of dietary phenethyl isothiocyanate in rats. Pharm Res. 2005; 22:1658-66.
12. Denis I, Cellerin L, Gregoire M, Blanquart C. Cisplatin in combination with Phenethyl Isothiocyanate (PEITC), a potential new therapeutic strategy for malignant pleural mesothelioma. Oncotarget. 2014; 5:11641-52. doi: 10.18632/oncotarget.2604.

13. Li Q, Zhan M, Chen W, Zhao B, Yang K, Yang J, Yi J, Huang Q, Mohan M, Hou Z, Wang J. Phenylethyl isothiocyanate reverses cisplatin resistance in biliary tract cancer cells via glutathionylation-dependent degradation of Mcl-1. Oncotarget. 2016; 7:10271-82. doi: 10.18632/ oncotarget.7171.

14. Tang T, Song X, Liu YF, Wang WY. PEITC reverse multidrug resistance of human gastric cancer SGC7901/DDP cell line. Cell Biol Int. 2014; 38:502-10.

15. Wang X, Govind S, Sajankila SP, Mi L, Roy R, Chung FL. Phenethyl isothiocyanate sensitizes human cervical cancer cells to apoptosis induced by cisplatin. Mol Nutr Food Res. 2011; 55:1572-81.

16. Gerhauser C. Cancer chemoprevention and nutriepigenetics: state of the art and future challenges. Top Curr Chem. 2013; 329:73-132.

17. Liu K, Cang S, Ma Y, Chiao JW. Synergistic effect of paclitaxel and epigenetic agent phenethyl isothiocyanate on growth inhibition, cell cycle arrest and apoptosis in breast cancer cells. Cancer Cell Int. 2013; 13:10.

18. Rajendran P, Ho E, Williams DE, Dashwood RH. Dietary phytochemicals, HDAC inhibition, and DNA damage/repair defects in cancer cells. Clin Epigenetics. 2011; 3:4.

19. Wang LG, Chiao JW. Prostate cancer chemopreventive activity of phenethyl isothiocyanate through epigenetic regulation (review). Int J Oncol. 2010; 37:533-39.

20. Wu X, Zhou QH, Xu K. Are isothiocyanates potential anticancer drugs? Acta Pharmacol Sin. 2009; 30:501-12.

21. Zhang H, Trachootham D, Lu W, Carew J, Giles FJ, Keating MJ, Arlinghaus RB, Huang P. Effective killing of Gleevecresistant CML cells with T315I mutation by a natural compound PEITC through redox-mediated mechanism. Leukemia. 2008; 22:1191-99.

22. Gao N, Budhraja A, Cheng S, Liu EH, Chen J, Yang Z, Chen D, Zhang Z, Shi X. Phenethyl isothiocyanate exhibits antileukemic activity in vitro and in vivo by inactivation of Akt and activation of JNK pathways. Cell Death Dis. 2011; 2:e140.

23. Lawson AP, Long MJ, Coffey RT, Qian Y, Weerapana E, El Oualid F, Hedstrom L. Naturally Occurring Isothiocyanates Exert Anticancer Effects by Inhibiting Deubiquitinating Enzymes. Cancer Res. 2015; 75:5130-42.

24. Weiler S, Ademokun JA, Norton JD. ID helix-loop-helix proteins as determinants of cell survival in B-cell chronic lymphocytic leukemia cells in vitro. Mol Cancer. 2015; 14:30.

25. $\mathrm{Wu} \mathrm{X}$, Kassie F, Mersch-Sundermann V. Induction of apoptosis in tumor cells by naturally occurring 
sulfur-containing compounds. Mutat Res. 2005; 589:81-102.

26. Peng J, Hu Q, Liu W, He X, Cui L, Chen X, Yang M, Liu H, Wei W, Liu S, Wang H. USP9X expression correlates with tumor progression and poor prognosis in esophageal squamous cell carcinoma. Diagn Pathol. 2013; 8:177.

27. Chen YJ, Ma YS, Fang Y, Wang Y, Fu D, Shen XZ. Power and promise of ubiquitin carboxyl-terminal hydrolase 37 as a target of cancer therapy. Asian Pac J Cancer Prev. 2013; 14:2173-79.

28. Zhou T, Li G, Cao B, Liu L, Cheng Q, Kong H, Shan C, Huang X, Chen J, Gao N. Downregulation of Mcl-1 through inhibition of translation contributes to benzyl isothiocyanate-induced cell cycle arrest and apoptosis in human leukemia cells. Cell Death Dis. 2013; 4:e515.

29. Nguyen LK, Kolch W, Kholodenko BN. When ubiquitination meets phosphorylation: a systems biology perspective of EGFR/MAPK signalling. Cell Commun Signal. 2013; 11:52.

30. Amerik AY, Hochstrasser M. Mechanism and function of deubiquitinating enzymes. Biochim Biophys Acta. 2004; 1695:189-207. doi: 10.1016/j.bbamcr.2004.10.003.

31. Ndubaku C, Tsui V. Inhibiting the deubiquitinating enzymes (DUBs). J Med Chem. 2015; 58:1581-95.

32. Nicholson B, Kumar S, Agarwal S, Eddins MJ, Marblestone JG, Wu J, Kodrasov MP, LaRocque JP, Sterner DE, Mattern MR. Discovery of Therapeutic Deubiquitylase Effector Molecules: current Perspectives. J Biomol Screen. 2014; 19:989-99.

33. Komander D, Clague MJ, Urbé S. Breaking the chains: structure and function of the deubiquitinases. Nat Rev Mol Cell Biol. 2009; 10:550-63.

34. Lanucara F, Eyers CE. Mass spectrometric-based quantitative proteomics using SILAC. Methods Enzymol. 2011; 500:133-50.

35. Borodovsky A, Ovaa H, Kolli N, Gan-Erdene T, Wilkinson KD, Ploegh HL, Kessler BM. Chemistry-based functional proteomics reveals novel members of the deubiquitinating enzyme family. Chem Biol. 2002; 9:1149-59.

36. Zhang Y, Talalay P. Mechanism of differential potencies of isothiocyanates as inducers of anticarcinogenic Phase 2 enzymes. Cancer Res. 1998; 58:4632-39.

37. García-Santisteban I, Peters GJ, Giovannetti E, Rodríguez JA. USP1 deubiquitinase: cellular functions, regulatory mechanisms and emerging potential as target in cancer therapy. Mol Cancer. 2013; 12:91.

38. Chen J, Dexheimer TS, Ai Y, Liang Q, Villamil MA, Inglese J, Maloney DJ, Jadhav A, Simeonov A, Zhuang Z. Selective and cell-active inhibitors of the USP1/ UAF1 deubiquitinase complex reverse cisplatin resistance in non-small cell lung cancer cells. Chem Biol. 2011; 18:1390-400.

39. Liang Q, Dexheimer TS, Zhang P, Rosenthal AS, Villamil MA, You C, Zhang Q, Chen J, Ott CA, Sun H, Luci DK, Yuan B, Simeonov A, et al. A selective USP1-UAF1 inhibitor links deubiquitination to DNA damage responses. Nat Chem Biol. 2014; 10:298-304.

40. Lasorella A, Benezra R, Iavarone A. The ID proteins: master regulators of cancer stem cells and tumour aggressiveness. Nat Rev Cancer. 2014; 14:77-91.

41. Mistry H, Hsieh G, Buhrlage SJ, Huang M, Park E, Cuny GD, Galinsky I, Stone RM, Gray NS, D'Andrea AD, Parmar K. Small-molecule inhibitors of USP1 target ID1 degradation in leukemic cells. Mol Cancer Ther. 2013; 12:2651-62.

42. Williams SA, Maecker HL, French DM, Liu J, Gregg A, Silverstein LB, Cao TC, Carano RA, Dixit VM. USP1 deubiquitinates ID proteins to preserve a mesenchymal stem cell program in osteosarcoma. Cell. 2011; 146:918-30.

43. Ekkebus R, van Kasteren SI, Kulathu Y, Scholten A, Berlin I, Geurink PP, de Jong A, Goerdayal S, Neefjes J, Heck AJ, Komander D, Ovaa H. On terminal alkynes that can react with active-site cysteine nucleophiles in proteases. J Am Chem Soc. 2013; 135:2867-70.

44. Kramer HB, Nicholson B, Kessler BM, Altun M. Detection of ubiquitin-proteasome enzymatic activities in cells: application of activity-based probes to inhibitor development. Biochim Biophys Acta. 2012; 1823:2029-37. doi: 10.1016/j.bbamcr.2012.05.014.

45. Oestergaard VH, Langevin F, Kuiken HJ, Pace P, Niedzwiedz W, Simpson LJ, Ohzeki M, Takata M, Sale JE, Patel KJ. Deubiquitination of FANCD2 is required for DNA crosslink repair. Mol Cell. 2007; 28:798-809.

46. Huang TT, Nijman SM, Mirchandani KD, Galardy PJ, Cohn MA, Haas W, Gygi SP, Ploegh HL, Bernards R, D’Andrea AD. Regulation of monoubiquitinated PCNA by DUB autocleavage. Nat Cell Biol. 2006; 8:339-47.

47. Andreopoulou E, Schweber SJ, Sparano JA, McDaid HM. Therapies for triple negative breast cancer. Expert Opin Pharmacother. 2015; 16:983-98.

48. Gerratana L, Fanotto V, Pelizzari G, Agostinetto E, Puglisi F. Do platinum salts fit all triple negative breast cancers? Cancer Treat Rev. 2016; 48:34-41.

49. Isakoff SJ, Mayer EL, He L, Traina TA, Carey LA, Krag KJ, Rugo HS, Liu MC, Stearns V, Come SE, Timms KM, Hartman AR, Borger DR, et al. TBCRC009: A Multicenter Phase II Clinical Trial of Platinum Monotherapy With Biomarker Assessment in Metastatic Triple-Negative Breast Cancer. J Clin Oncol. 2015; 33:1902-09.

50. Cramer JM, Teran-Garcia M, Jeffery EH. Enhancing sulforaphane absorption and excretion in healthy men through the combined consumption of fresh broccoli sprouts and a glucoraphanin-rich powder. Br J Nutr. 2012; 107:1333-38.

51. Di Veroli GY, Fornari C, Wang D, Mollard S, Bramhall JL, Richards FM, Jodrell DI. Combenefit: an interactive platform for the analysis and visualization of drug combinations. Bioinformatics. 2016; 32:2866-68. 
52. Cao J, Yan Q. Histone ubiquitination and deubiquitination in transcription, DNA damage response, and cancer. Front Oncol. 2012; 2:26.

53. Vissers JH, Nicassio F, van Lohuizen M, Di Fiore PP, Citterio E. The many faces of ubiquitinated histone H2A: insights from the DUBs. Cell Div. 2008; 3:8.

54. Nicassio F, Corrado N, Vissers JH, Areces LB, Bergink S, Marteijn JA, Geverts B, Houtsmuller AB, Vermeulen W, Di Fiore PP, Citterio E. Human USP3 is a chromatin modifier required for $\mathrm{S}$ phase progression and genome stability. Curr Biol. 2007; 17:1972-77.

55. Udeshi ND, Mani DR, Eisenhaure T, Mertins P, Jaffe JD, Clauser KR, Hacohen N, Carr SA. Methods for quantification of in vivo changes in protein ubiquitination following proteasome and deubiquitinase inhibition. Mol Cell Proteomics. 2012; 11:148-59.

56. Dantuma NP, Groothuis TA, Salomons FA, Neefjes J. A dynamic ubiquitin equilibrium couples proteasomal activity to chromatin remodeling. J Cell Biol. 2006; 173:19-26.

57. Vlachostergios PJ, Patrikidou A, Daliani DD, Papandreou $\mathrm{CN}$. The ubiquitin-proteasome system in cancer, a major player in DNA repair. Part 1: post-translational regulation. J Cell Mol Med. 2009; 13:3006-18.

58. Mimnaugh EG, Yunmbam MK, Li Q, Bonvini P, Hwang SG, Trepel J, Reed E, Neckers L. Prevention of cisplatinDNA adduct repair and potentiation of cisplatin-induced apoptosis in ovarian carcinoma cells by proteasome inhibitors. Biochem Pharmacol. 2000; 60:1343-54.

59. Yao T, Song L, Xu W, DeMartino GN, Florens L, Swanson SK, Washburn MP, Conaway RC, Conaway JW, Cohen RE. Proteasome recruitment and activation of the Uch37 deubiquitinating enzyme by Adrm1. Nat Cell Biol. 2006; 8:994-1002.

60. Siddik ZH. Cisplatin: mode of cytotoxic action and molecular basis of resistance. Oncogene. 2003; 22:7265-79.

61. Sourisseau T, Helissey C, Lefebvre C, Ponsonnailles F, Malka-Mahieu H, Olaussen KA, André F, Vagner S, Soria JC. Translational regulation of the mRNA encoding the ubiquitin peptidase USP1 involved in the DNA damage response as a determinant of Cisplatin resistance. Cell Cycle. 2016; 15:295-302.

62. Fong S, Itahana Y, Sumida T, Singh J, Coppe JP, Liu Y, Richards PC, Bennington JL, Lee NM, Debs RJ, Desprez PY. Id-1 as a molecular target in therapy for breast cancer cell invasion and metastasis. Proc Natl Acad Sci USA. 2003; 100:13543-48.

63. Nair R, Teo WS, Mittal V, Swarbrick A. ID proteins regulate diverse aspects of cancer progression and provide novel therapeutic opportunities. Mol Ther. 2014; 22:1407-15. doi: 10.1038/mt.2014.83.

64. Cotto-Rios XM, Jones MJ, Busino L, Pagano M, Huang TT. APC/CCdh1-dependent proteolysis of USP1 regulates the response to UV-mediated DNA damage. J Cell Biol. 2011; 194:177-86.
65. Yin P, Kawamura T, He M, Vanaja DK, Young CY. Phenethyl isothiocyanate induces cell cycle arrest and reduction of alpha- and beta-tubulin isotypes in human prostate cancer cells. Cell Biol Int. 2009; 33:57-64.

66. Joo HY, Zhai L, Yang C, Nie S, Erdjument-Bromage H, Tempst P, Chang C, Wang H. Regulation of cell cycle progression and gene expression by $\mathrm{H} 2 \mathrm{~A}$ deubiquitination. Nature. 2007; 449:1068-72.

67. Vlachostergios PJ, Patrikidou A, Daliani DD, Papandreou $\mathrm{CN}$. The ubiquitin-proteasome system in cancer, a major player in DNA repair. Part 2: transcriptional regulation. J Cell Mol Med. 2009; 13:3019-31.

68. Lasorella A, Rothschild G, Yokota Y, Russell RG, Iavarone A. Id2 mediates tumor initiation, proliferation, and angiogenesis in Rb mutant mice. Mol Cell Biol. 2005; 25:3563-74.

69. Wang XH, Cavell BE, Syed Alwi SS, Packham G. Inhibition of hypoxia inducible factor by phenethyl isothiocyanate. Biochem Pharmacol. 2009; 78:261-72.

70. Xiao D, Singh SV. Phenethyl isothiocyanate inhibits angiogenesis in vitro and ex vivo. Cancer Res. 2007; 67:2239-46.

71. Boyanapalli SS, Paredes-Gonzalez X, Fuentes F, Zhang C, Guo Y, Pung D, Saw CL, Kong AN. Nrf2 knockout attenuates the anti-inflammatory effects of phenethyl isothiocyanate and curcumin. Chem Res Toxicol. 2014; 27:2036-43.

72. Wang X, Di Pasqua AJ, Govind S, McCracken E, Hong C, Mi L, Mao Y, Wu JY, Tomita Y, Woodrick JC, Fine RL, Chung FL. Selective depletion of mutant p53 by cancer chemopreventive isothiocyanates and their structureactivity relationships. J Med Chem. 2011; 54:809-16.

73. Schweitzer K, Naumann M. CSN-associated USP48 confers stability to nuclear NF-kappaB/RelA by trimming K48linked Ub-chains. Biochim Biophys Acta. 2015; 1853:45369. doi: 10.1016/j.bbamcr.2014.11.028.

74. Xu C, Shen G, Chen C, Gélinas C, Kong AN. Suppression of NF-kappaB and NF-kappaB-regulated gene expression by sulforaphane and PEITC through IkappaBalpha, IKK pathway in human prostate cancer PC-3 cells. Oncogene. 2005; 24:4486-95.

75. Karin M, Greten FR. NF-kappaB: linking inflammation and immunity to cancer development and progression. Nat Rev Immunol. 2005; 5:749-59.

76. Dou Y, Lin J, Shu H, Jiang N. Role of ubiquitin-specific peptidase 22 in carcinogenesis of human pharyngeal squamous cell carcinoma. Mol Med Rep. 2014; 10:2973-78.

77. Glinsky GV, Berezovska O, Glinskii AB. Microarray analysis identifies a death-from-cancer signature predicting therapy failure in patients with multiple types of cancer. $\mathrm{J}$ Clin Invest. 2005; 115:1503-21.

78. Liu YL, Jiang SX, Yang YM, Xu H, Liu JL, Wang $\mathrm{XS}$. USP22 acts as an oncogene by the activation of 
BMI-1-mediated INK4a/ARF pathway and Akt pathway. Cell Biochem Biophys. 2012; 62:229-35.

79. Schrecengost RS, Dean JL, Goodwin JF, Schiewer MJ, Urban MW, Stanek TJ, Sussman RT, Hicks JL, Birbe RC, Draganova-Tacheva RA, Visakorpi T, DeMarzo AM, McMahon SB, Knudsen KE. USP22 regulates oncogenic signaling pathways to drive lethal cancer progression. Cancer Res. 2014; 74:272-86.

80. Xiao H, Tian Y, Yang Y, Hu F, Xie X, Mei J, Ding F. USP22 acts as an oncogene by regulating the stability of cyclooxygenase-2 in non-small cell lung cancer. Biochem Biophys Res Commun. 2015; 460:703-08.

81. Atanassov BS, Dent SY. USP22 regulates cell proliferation by deubiquitinating the transcriptional regulator FBP1. EMBO Rep. 2011; 12:924-30.

82. Chen PY, Lin KC, Lin JP, Tang NY, Yang JS, Lu KW, Chung JG. Phenethyl Isothiocyanate (PEITC) Inhibits the Growth of Human Oral Squamous Carcinoma HSC-3 Cells through $\mathrm{G}(0) / \mathrm{G}(1)$ Phase Arrest and Mitochondria-Mediated Apoptotic Cell Death. Evid Based Complement Alternat Med. 2012; 2012:718320. doi: 10.1155/2012/718320.

83. Wang LG, Liu XM, Fang Y, Dai W, Chiao FB, Puccio GM, Feng J, Liu D, Chiao JW. De-repression of the p21 promoter in prostate cancer cells by an isothiocyanate via inhibition of HDACs and c-Myc. Int J Oncol. 2008; 33:375-80.

84. Lai KC, Hsu SC, Kuo CL, Ip SW, Yang JS, Hsu YM, Huang $\mathrm{HY}, \mathrm{Wu} \mathrm{SH}$, Chung JG. Phenethyl isothiocyanate inhibited tumor migration and invasion via suppressing multiple signal transduction pathways in human colon cancer HT29 cells. J Agric Food Chem. 2010; 58:11148-55.

85. Mevissen TE, Hospenthal MK, Geurink PP, Elliott PR, Akutsu M, Arnaudo N, Ekkebus R, Kulathu Y, Wauer T, El Oualid F, Freund SM, Ovaa H, Komander D. OTU deubiquitinases reveal mechanisms of linkage specificity and enable ubiquitin chain restriction analysis. Cell. 2013; 154:169-84.

86. Totsukawa G, Kaneko Y, Uchiyama K, Toh H, Tamura K, Kondo H. VCIP135 deubiquitinase and its binding protein, WAC, in p97ATPase-mediated membrane fusion. EMBO J. 2011; 30:3581-93.

87. Anighoro A, Bajorath J, Rastelli G. Polypharmacology: challenges and opportunities in drug discovery. J Med Chem. 2014; 57:7874-87.

88. Borodovsky A, Kessler BM, Casagrande R, Overkleeft HS, Wilkinson KD, Ploegh HL. A novel active sitedirected probe specific for deubiquitylating enzymes reveals proteasome association of USP14. EMBO J. 2001; 20:5187-96.

89. Weerapana E, Speers AE, Cravatt BF. Tandem orthogonal proteolysis-activity-based protein profiling (TOP-ABPP) - a general method for mapping sites of probe modification in proteomes. Nat Protoc. 2007; 2:1414-25.
90. Weerapana E, Wang C, Simon GM, Richter F, Khare S, Dillon MB, Bachovchin DA, Mowen K, Baker D, Cravatt BF. Quantitative reactivity profiling predicts functional cysteines in proteomes. Nature. 2010; 468:790-95.

91. Geary N. Understanding synergy. Am J Physiol Endocrinol Metab. 2013; 304:E237-53.

92. Bliss CI. The Toxicity of Poisons Applied Jointly. Ann Appl Biol. 1939; 26:585-615.

93. VanderLinden RT, Hemmis CW, Schmitt B, Ndoja A, Whitby FG, Robinson H, Cohen RE, Yao T, Hill CP. Structural basis for the activation and inhibition of the UCH37 deubiquitylase. Mol Cell. 2015; 57:901-11.

94. Cataldo F, Peche LY, Klaric E, Brancolini C, Myers MP, Demarchi F, Schneider C. CAPNS1 regulates USP1 stability and maintenance of genome integrity. Mol Cell Biol. 2013; 33:2485-96.

95. Nijman SM, Huang TT, Dirac AM, Brummelkamp TR, Kerkhoven RM, D'Andrea AD, Bernards R. The deubiquitinating enzyme USP1 regulates the Fanconi anemia pathway. Mol Cell. 2005; 17:331-39.

96. Cui J, Song Y, Li Y, Zhu Q, Tan P, Qin Y, Wang HY, Wang RF. USP3 inhibits type I interferon signaling by deubiquitinating RIG-I-like receptors. Cell Res. 2014; 24:400-16.

97. Sharma N, Zhu Q, Wani G, He J, Wang QE, Wani AA. USP 3 counteracts RNF168 via deubiquitinating H2A and $\gamma \mathrm{H} 2 \mathrm{AX}$ at lysine 13 and 15. Cell Cycle. 2014; 13:106-14.

98. Jacq X, Kemp M, Martin NM, Jackson SP. Deubiquitylating enzymes and DNA damage response pathways. Cell Biochem Biophys. 2013; 67:25-43.

99. Magraoui FE, Reidick C, Meyer HE, Platta HW. Autophagy-Related Deubiquitinating Enzymes Involved in Health and Disease. Cells. 2015; 4:596-621.

100. Vijayakumaran R, Tan KH, Miranda PJ, Haupt S, Haupt Y. Regulation of Mutant p53 Protein Expression. Front Oncol. 2015; 5:284.

101. Yuan J, Luo K, Zhang L, Cheville JC, Lou Z. USP10 regulates $\mathrm{p} 53$ localization and stability by deubiquitinating p53. Cell. 2010; 140:384-96.

102. Liu J, Xia H, Kim M, Xu L, Li Y, Zhang L, Cai Y, Norberg HV, Zhang T, Furuya T, Jin M, Zhu Z, Wang H, et al. Beclin 1 controls the levels of $\mathrm{p} 53$ by regulating the deubiquitination activity of USP10 and USP13. Cell. 2011; 147:223-34.

103. Boulkroun S, Ruffieux-Daidié D, Vitagliano JJ, Poirot O, Charles RP, Lagnaz D, Firsov D, Kellenberger S, Staub O. Vasopressin-inducible ubiquitin-specific protease 10 increases $\mathrm{ENaC}$ cell surface expression by deubiquitylating and stabilizing sorting nexin 3. Am J Physiol Renal Physiol. 2008; 295:F889-900.

104. Bomberger JM, Barnaby RL, Stanton BA. The deubiquitinating enzyme USP10 regulates the endocytic 
recycling of CFTR in airway epithelial cells. Channels (Austin). 2010; 4:150-54.

105. Yu M, Liu K, Mao Z, Luo J, Gu W, Zhao W. USP11 Is a Negative Regulator to $\gamma \mathrm{H} 2 \mathrm{AX}$ Ubiquitylation by RNF8/ RNF168. J Biol Chem. 2016; 291:959-67.

106. Maertens GN, El Messaoudi-Aubert S, Elderkin S, Hiom K, Peters G. Ubiquitin-specific proteases 7 and 11 modulate Polycomb regulation of the INK4a tumour suppressor. EMBO J. 2010; 29:2553-65.

107. Sun W, Tan X, Shi Y, Xu G, Mao R, Gu X, Fan Y, Yu Y, Burlingame S, Zhang H, Rednam SP, Lu X, Zhang T, et al. USP11 negatively regulates TNFalpha-induced NF-kappaB activation by targeting on IkappaBalpha. Cell Signal. 2010; 22:386-94.

108. Lee EW, Seong D, Seo J, Jeong M, Lee HK, Song J. USP11-dependent selective cIAP2 deubiquitylation and stabilization determine sensitivity to Smac mimetics. Cell Death Differ. 2015; 22:1463-76.

109. Jakubikova J, Cervi D, Ooi M, Kim K, Nahar S, Klippel S, Cholujova D, Leiba M, Daley JF, Delmore J, Negri J, Blotta S, McMillin DW, et al. Anti-tumor activity and signaling events triggered by the isothiocyanates, sulforaphane and phenethyl isothiocyanate, in multiple myeloma. Haematologica. 2011; 96:1170-79.

110. Gu Y, Jones AE, Yang W, Liu S, Dai Q, Liu Y, Swindle CS, Zhou D, Zhang Z, Ryan TM, Townes TM, Klug CA, Chen D, Wang H. The histone H2A deubiquitinase Usp16 regulates hematopoiesis and hematopoietic stem cell function. Proc Natl Acad Sci USA. 2016; 113:E51-60.

111. Zhang Z, Yang H, Wang H. The histone H2A deubiquitinase USP16 interacts with HERC2 and fine-tunes cellular response to DNA damage. J Biol Chem. 2014; 289:32883-94.

112. Tang B, Tang F, Li B, Yuan S, Xu Q, Tomlinson S, Jin J, Hu W, He S. High USP22 expression indicates poor prognosis in hepatocellular carcinoma. Oncotarget. 2015; 6:12654-67. doi: 10.18632/oncotarget.3705.

113. Rodríguez-Navarro S. Insights into SAGA function during gene expression. EMBO Rep. 2009; 10:843-50.

114. Atanassov BS, Evrard YA, Multani AS, Zhang Z, Tora L, Devys D, Chang S, Dent SY. Gen5 and SAGA regulate shelterin protein turnover and telomere maintenance. Mol Cell. 2009; 35:352-64.

115. Zhang XY, Pfeiffer HK, Thorne AW, McMahon SB. USP22, an hSAGA subunit and potential cancer stem cell marker, reverses the polycomb-catalyzed ubiquitylation of histone H2A. Cell Cycle. 2008; 7:1522-24.

116. Cole AJ, Clifton-Bligh RJ, Marsh DJ. Ubiquitination and cancer: histone $\mathrm{H} 2 \mathrm{~B}$ monoubiquitination - roles to play in human malignancy. Endocr Relat Cancer. 2015; 22:T19-33.

117. Chou YC, Chang MY, Wang MJ, Liu HC, Chang SJ, Harnod T, Hung CH, Lee HT, Shen CC, Chung JG. Phenethyl isothiocyanate alters the gene expression and the levels of protein associated with cell cycle regulation in human glioblastoma GBM 8401 cells. Environ Toxicol. 2017; 32:176-187.

118. Conaway RC, Conaway JW. The INO80 chromatin remodeling complex in transcription, replication and repair. Trends Biochem Sci. 2009; 34:71-77.

119. Randles L, Anchoori RK, Roden RB, Walters KJ. The Proteasome Ubiquitin Receptor hRpn13 and Its Interacting Deubiquitinating Enzyme Uch37 Are Required for Proper Cell Cycle Progression. J Biol Chem. 2016; 291:8773-83. 